\title{
Long-Term Changes of Open-Surface Water Bodies in the Yangtze River Basin Based on the Google Earth Engine Cloud Platform
}

\author{
Yue Deng ${ }^{1}$, Weiguo Jiang ${ }^{1,2, * \mathbb{C}}$, Zhenghong Tang ${ }^{3}$, Ziyan Ling ${ }^{2,4}$ and Zhifeng $\mathrm{Wu}^{5}$ \\ 1 Beijing Key Laboratory for Remote Sensing of Environment and Digital Cities, Faculty of Geographical \\ Science, Beijing Normal University, Beijing 100875, China; dengyue@mail.bnu.edu.cn \\ 2 Key Laboratory of Environment Change and Resources Use in Beibu Gulf, Nanning Normal University, \\ Nanning 530001, China; lingziyan@nnnu.edu.cn \\ 3 Community and Regional Planning Program, College of Architecture, University of Nebraska-Lincoln, \\ Lincoln, NE 68588-0105, USA; ztang2@unl.edu \\ 4 School of Geography and Planning, Nanning Normal University, Nanning 530001, China \\ 5 School of Geographical Sciences, Guangzhou University, Guangzhou 510006, China; zfwu@gzhu.edu.cn \\ * Correspondence: jiangweiguo@bnu.edu.cn
}

Received: 31 July 2019; Accepted: 18 September 2019; Published: 21 September 2019

\begin{abstract}
The spatiotemporal changes of open-surface water bodies in the Yangtze River Basin (YRB) have profound influences on sustainable economic development, and are also closely relevant to water scarcity in China. However, long-term changes of open-surface water bodies in the YRB have remained poorly characterized. Taking advantage of the Google Earth Engine (GEE) cloud platform, this study processed 75,593 scenes of Landsat images to investigate the long-term changes of open-surface water bodies in the YRB from 1984 to 2018. In this study, we adopted the percentile-based image composite method to collect training samples and proposed a multiple index water detection rule (MIWDR) to quickly extract the open-surface water bodies. The results indicated that (1) the MIWDR is suitable for the long-term and large-scale Landsat water bodies mapping, especially in the urban regions. (2) The areas of permanent water bodies and seasonal water bodies were $29,076.70 \mathrm{~km}^{2}$ and $21,526.24 \mathrm{~km}^{2}$, accounting for $57.46 \%$ and $42.54 \%$ of the total open-surface water bodies in the YRB, respectively. (3) The permanent water bodies in the YRB increased along with the decreases in the seasonal water bodies from 1984 to 2018. In general, the total open-surface surface water bodies in the YRB experienced an increasing trend, with an obvious spatial heterogeneity. (4) The changes of open-surface water bodies were associated with the climate changes and intense human activities in the YRB, however, the influences varied among different regions and need to be further investigated in the future.
\end{abstract}

Keywords: open-surface water bodies; Landsat image; Google Earth Engine; Yangtze River Basin

\section{Introduction}

Water resources and services play a critical role in economic growth and environmental sustainability. As the essential components of water resources, open-surface water bodies, including lakes, reservoirs, rivers, streams and ponds, provide a series of ecosystem services, such as water supply and regulation, climate regulation, and food production [1,2]. However, from 1984 to 2015, permanent water bodies decreased by almost $90,000 \mathrm{~km}^{2}$ due to climate changes and human activities [3]. China has the largest population in the world and has experienced fast development over the past years. Whereas, the uneven spatial distribution of water resources has been an important constraining factor which has made the water scarcity more severe in China, especially in the northern part of 
the country [4]. In order to alleviate the problem, the South-to-North Water Diversion Project was proposed to draw water from the Yangtze River Basin (YRB) and supply it to the dry northern regions. Therefore, monitoring the dynamics of open-surface water bodies in the YRB is not only necessary for regional sustainable economic development, but also has great importance for the whole country.

Remote sensing provides a convenient platform for monitoring the spatiotemporal changes of open-surface water bodies by using a variety of data sources, such as moderate resolution imaging spectrometer (MODIS) images [5-9], Landsat images [10-14], and Sentinel images [15-17]. However, traditional studies in open-surface water bodies usually use fewer images during a specified period for a large-scale region, as it is difficult to process huge amounts of remote sensing images [18]. In recent years, a cloud-based platform called the Google Earth Engine (GEE) has been developed to facilitate large-scale analysis of geospatial data [19-22]. Up to now, the GEE has been widely used in large-scale applications, including mapping of urban land [23], paddy rice [24], wetlands [25,26], as well as open-surface water bodies [3,27,28]. For example, Pekel et al. [3] achieved the mapping of long-term global open-surface water bodies from 1984 to 2015 based on the GEE platform. The spatiotemporal changes of open-surface water bodies in the contiguous United States from 1984 to 2016 were also explored based on the GEE [28]. Therefore, the GEE provides us with a new insight to understand the long-term changes of the open-surface water bodies in the YRB.

Water index followed by thresholding was widely used to extract surface water bodies for their conveniences [29]. These common water indices include the normalized difference water index (NDWI) [30], modified normalized difference water index (MNDWI) [31], and automated water extraction index (AWEI) [32]. However, an ideal single threshold to distinguish between water bodies and non-water bodies is difficult to be determined because the spectral signature of water bodies varies in space and time [29]. Another approach uses a range of predictor variables, including original spectral bands, water indices, and others to develop the classification models, thereby accounting for uncertainty in the threshold values. The common classification models contain support vector machines (SVM), maximum likelihood (ML), random forest (RF) [33,34], and so on. For these classification models, the model accuracy is affected by the training samples, predictor variables, and model parameters. Moreover, classification models often need more time to generate the classification results. However, for large-scale mapping of open-surface water bodies in the GEE, a simple method with high accuracy for water extraction needs to be developed. Recently, Zou et al. [28] established a water detection rule to extract long-term open-surface water bodies over the United States based on the MNDWI, a normalized difference vegetation index (NDVI) [35] and an enhanced vegetation index (EVI) [36]. If a pixel meets the following criteria: EVI $<0.1$ and (MNDWI $>$ NDVI or MNDWI $>$ EVI), then it is classified as a water body [28]. The water detection rule proposed by Zou et al. [28] has also been adopted by Zhou et al. [37] in the GEE platform to monitor the lake dynamics on the Mongolian Plateau. Using the water detection rule can achieve high accuracy, along with fast efficiency. Therefore, it is suited for the large-scale application in the GEE. However, there were few water detection rules for large-scale applications. Therefore, it is necessary to conduct the studies to develop new water detection rules for the mapping of open-surface water bodies.

There were a few studies about the changes of open-surface water bodies in the YRB. Especially, the middle and lower reaches of the YRB obtained more attention due to a large number of surface water bodies and the high flood risk. For example, Wang et al. [18] explored the maximal and minimal surface water bodies in the year of 1990, 2000, 2010, and 2017 in the middle YRB based on Landsat images and the GEE platform. Other studies paid more attention to the long-term changes of important lakes in the YRB, including Poyang Lake and Dongting Lake [38-40]. However, due to the climate changes and human activities, the surface water bodies in the source and upper reaches of YRB also experienced remarkable changes, which also need to be explored. Recently, Rao et al. [41] investigated the dynamic changes of surface water bodies in the YRB based on MODIS products from 2000 to 2016. In general, few studies investigated the long-term changes of open-surface water bodies for the whole YRB using high-resolution Landsat images. 
Thus, the objectives of this study are (1) to propose a new framework to quickly collect samples and detect open-surface water bodies in the GEE platform and (2) to analyze the long-term changes of the open-surface water bodies in the YRB from 1984 to 2018 based on the GEE platform and all available Landsat images. Furthermore, the study can reinforce the understanding of long-term changes of open-surface water bodies in the YRB and facilitate the development of water resource management in the YRB.

\section{Materials and Methods}

\subsection{Study Area}

The YRB is located in southern China $\left(90-121^{\circ} \mathrm{E}\right.$ and $\left.24-36^{\circ} \mathrm{N}\right)$ (Figure 1). It covers about $1.8 \times 10^{6} \mathrm{~km}^{2}$, representing one-fifth of China's land area. The YRB is characterized by complex geographical environments, with plateaus and mountains in the western region, basins, and hills in the middle part, and plains in the eastern area. In this study, the YRB was divided into four sub-basins: the source of the YRB (SYRB), the upper reaches of the YRB (UYRB), the middle reaches of the YRB (MYRB), and the lower reaches of the YRB (LYRB). The SYRB is located in the Tibetan Plateau, and the climate in SYRB is characterized by the low annual precipitation and cold average temperature. The URYB mainly consists of western mountains and eastern Sichuan Basin. The precipitation in the UYRB varies from $500 \mathrm{~mm}$ to the $1000 \mathrm{~mm}$. The precipitation in MRYB and SYRB varies from $1000 \mathrm{~mm}$ to $1900 \mathrm{~mm}$ (Figure S1). Apart from the western YRB in the Tibetan Plateau, the climate in the eastern UYRB, MYRB, and LYRB is mostly controlled by the Indian summer monsoon and the East Asian summer monsoon, which lead to the annual cycle of dry and wet seasons [42]. Overall, precipitations from May to October were estimated to be about $70 \%-90 \%$ of the annual total precipitation in the YRB [43].

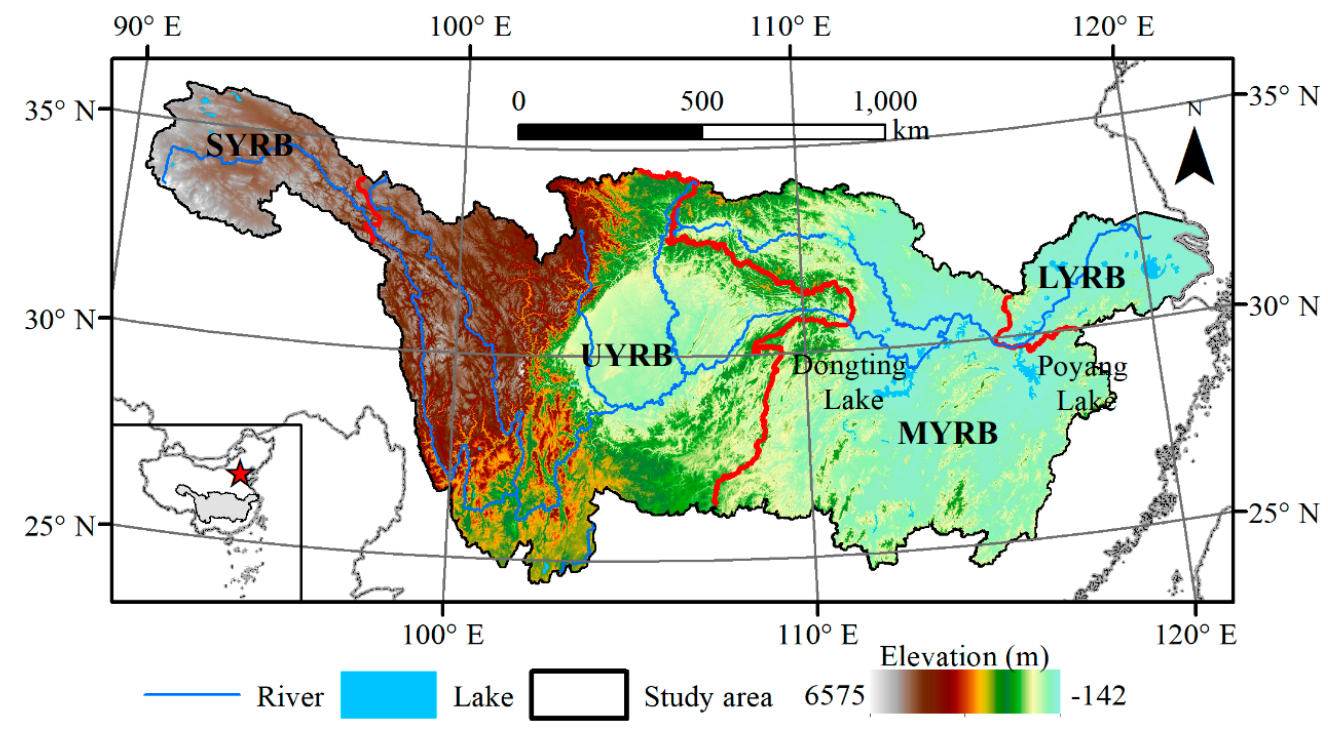

Figure 1. The location of the study area.

\subsection{Data}

This study used all available Landsat 5, 7, and 8 surface reflectance images of the entire YRB in the GEE platform from 1984 to 2018. The Landsat 5 and 7 surface reflectance datasets were generated from the Landsat ecosystem disturbance adaptive processing system (LEDAPS) algorithm, and the Landsat 8 surface reflectance products were generated from the Landsat surface reflectance code (LaSRC) algorithm [44]. Six spectral bands, including blue band, green band, red band, near-infrared band, short-wave infrared band 1, and short-wave infrared band 2, had a spatial resolution of $30 \mathrm{~m}$ and were used to extract water bodies. The total number of these images was 75,593, including 35,642 
Landsat 5 from 1984 to 2013, 28,745 Landsat 7 from 1999 to 2018, and 11,206 Landsat 8 from 2013 to 2018. The spatial distribution, temporal distribution, and seasonal distribution of total observation counts from 1984 to 2018 are presented in Figure 2.

(a)
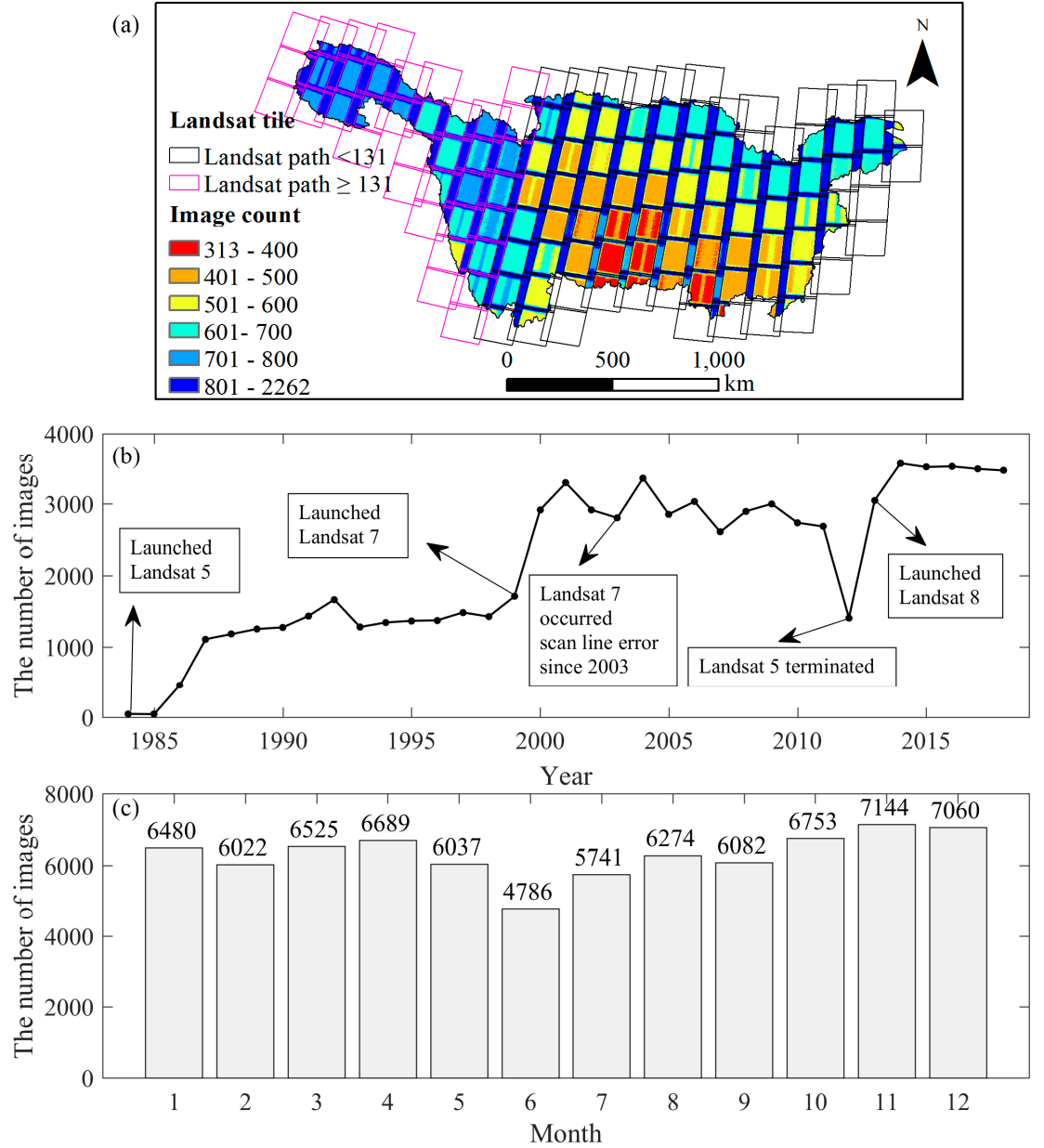

Figure 2. The Landsat image of the study area. (a-c) indicates the spatial distribution, temporal distribution, and seasonal distribution.

Moreover, the Sentinel-2 images with a spatial resolution of $10 \mathrm{~m}$ were used to evaluate the accuracy of the extracted water bodies in the YRB. PERSIANN-CDR daily precipitation products from 1984 to 2018 with a spatial resolution of $0.25^{\circ}$ were used to analyze the temporal trend of precipitation in the YRB [45]. The JRC Global Surface Water Occurrence Layer was also used as ancillary data to filter the misclassifications, such as hill shadow [3]. These data can be accessed through the GEE's public data catalog. In addition, FROM-GLC data [46] and SRTM DEM data were collected to display the land cover and elevation in the YRB, respectively.

\subsection{Methods}

\subsubsection{Sample Collection Based on Percentile Composite Images}

A total of 14 out of 122 Landsat tiles that overlap with the YRB were first selected. The selected tiles were relatively evenly located in the YRB, with different land cover types (Figure 3). Moreover, these tiles cover the typical open-surface water bodies, such as Dongting Lake, urban lakes, plateau lakes, and rivers. For each tile, all the images from 1984 to 2018 can be regarded as an image collection. Firstly, for each image in the image collection, the cloud, cloud shadow, and snow/ice were masked by Landsat quality band generated by the Fmask algorithm [47]. Each image has six 
spectral bands, including blue band, green band, red band, near-infrared band, short-wave infrared band 1, and short-wave infrared band 2 . Then, the study calculated the percentile value of surface reflectance for each pixel based on the single spectral bands in the image collection. Finally, six single spectral bands were composited into a single image. The composited image was called the cloud-free percentile composite image. The percentile-based image composite method was easily conducted in the GEE platform through the built-in function "ee.Reducer.percentile". The surface reflectance exhibits intra-annual changes due to phenology and sun angle differences [48]. Therefore, the percentile composite method can be used to generate season-variation images. For example, Donchyts et al. [49] revealed that the percentile range of $15 \%-55 \%$ of all Landsat 8 top-of-atmosphere reflectance products from 2013-2015 was suitable for permanent water detection over the Murray-Darling Basin. In this study, $10 \%, 20 \%, 30 \%, 40 \%, 50 \%, 60 \%, 70 \%, 80 \%$, and $90 \%$ percentile composite images were calculated for each tile. As shown in Figure 3, the percentile images show the seasonal variations, and the use of lower percentiles has a higher chance to represent a larger amount of surface water bodies.

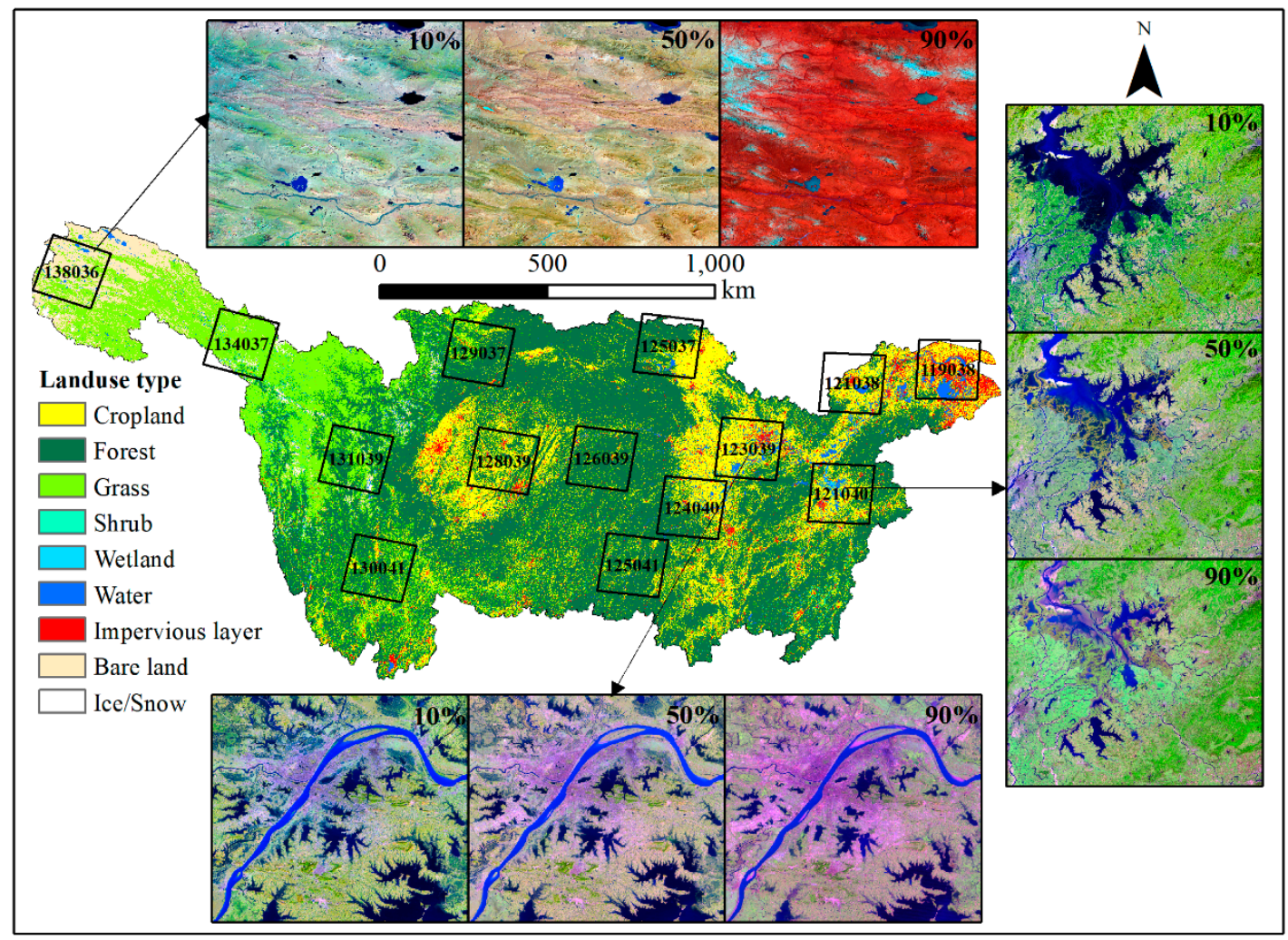

Figure 3. The spatial distribution of sampling plots and $10 \%, 50 \%$, and $90 \%$ percentile composite images for three sampling plots. The number in sampling plots indicates the Landsat path (the first three digits) and row (The last three digits).

The $90 \%$ percentile composite image collection (14 Landsat tiles are regarded as an image collection) represented the minimum extent of surface water bodies and were used to randomly generate water samples. The water samples were expected to be identified as water bodies in the other eight percentile composite image collections. Moreover, the $10 \%$ percentile composite image collection indicated the minimum extent of non-water bodies, and was used to randomly generate non-water samples. The non-water samples were expected to be identified as non-water bodies in the other eight percentile composite image collections. Then, by further visual interpretation, the samples which had a stable type but a changing spectral reflectance were retained. Finally, for each percentile composite image collection, the study collected 10,665 samples, including 1427 water samples and 9238 non-water samples. Therefore, the 9 percentile image collections result in 95,985 samples, including 12,843 water 
samples and 83,142 non-water samples. The number of samples was enough to establish a water detection rule.

\subsubsection{Water Extraction Based on Water Detection Rule}

Based on Zou et al. [28], the study used NDWI, AWEI, NDVI, and EVI to develop a multiple index water detection rule (MIWDR). In particular, AWEI has two versions, including $\mathrm{AWEI}_{\text {nsh }}$ and $\mathrm{AWEI}_{\mathrm{sh}}$ [32]. The $\mathrm{AWEI} \mathrm{I}_{\text {nsh }}$ is suited for these areas where shadows are not a major problem. $\mathrm{AWEI}_{\text {sh }}$ can effectively eliminate shadow pixels but misclassify highly reflective surfaces as water [32]. If a pixel meets the following criteria: $\left(\mathrm{AWEI}_{n s h}-\mathrm{AWEI}_{\mathrm{sh}}>-0.1\right)$ and $(\mathrm{MNDWI}>\mathrm{NDVI}$ or MNDWI $>$ EVI), then it was classified as water body. Figure 4 shows the scatter density plots of all samples. For water samples, only $1.21 \%$ were misclassified into non-water bodies. As for non-water samples, only $1.47 \%$ were misclassified into water bodies.
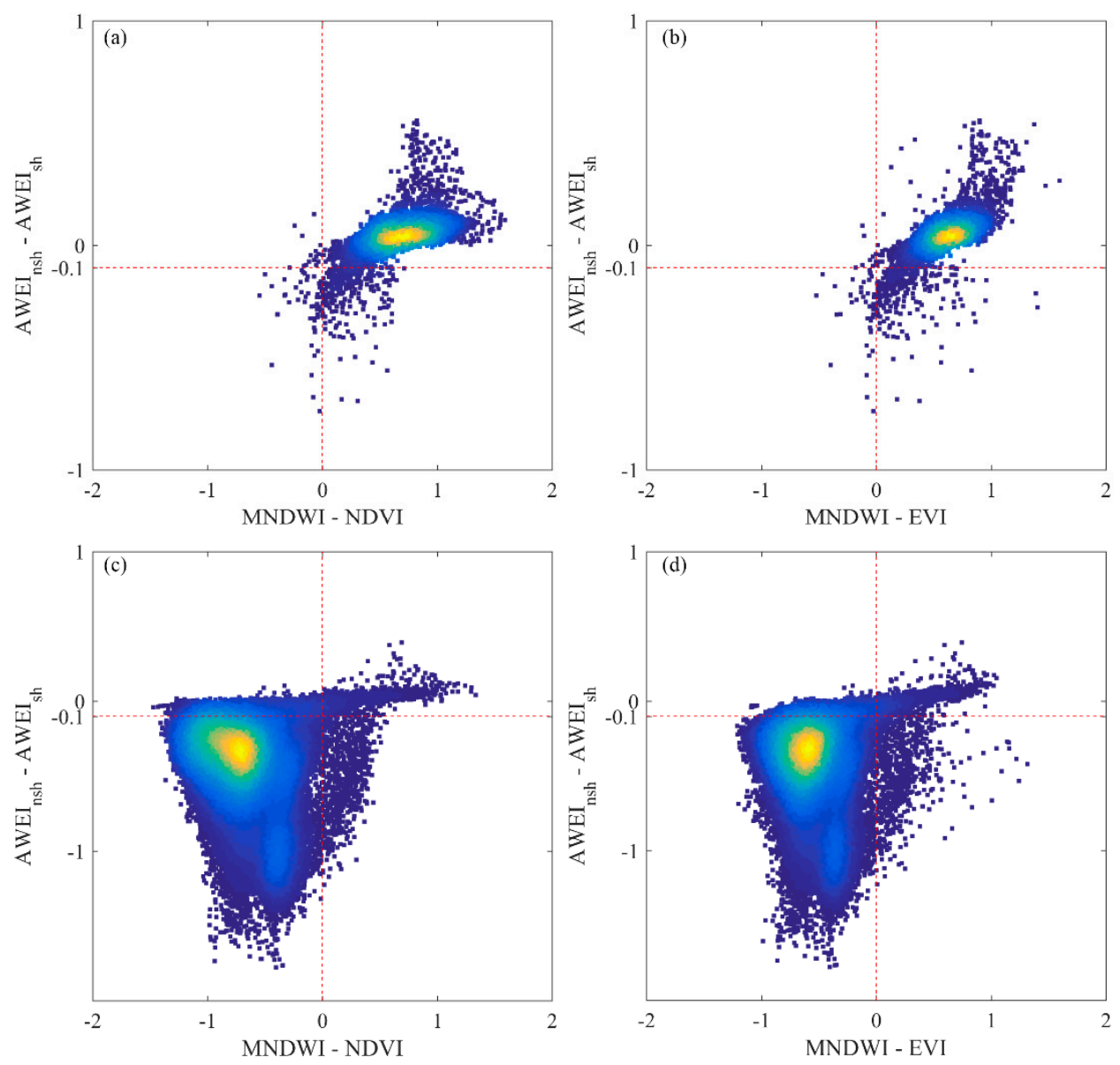

Figure 4. The scatter density of samples. (a,b) indicates the water samples. (c,d) indicates the non-water samples.

In order to obtain better water bodies mapping in the YRB, we compared the MIWDR with the method in Zou et al. [28]. In general, both of two rules showed good performance on the open-surface water bodies, such as large lakes and rivers (Figure S2). The MIWDR performed better than Zou et al. [28] in urban environments (Figure S3). However, the rule of Zou et al. [28] performed better than the MIWDR for these water bodies in the plateau regions (Figure S4). Therefore, we used the Landsat path as an index to determine the suitable method to extract open-surface water bodies. If the Landsat path of an image was less than 131, then the MIWDR was used. If the Landsat path of an image was greater than or equal to 131, then the water detection rule proposed by Zou et al. [28] 
was used. The Landsat path of 131 was chosen by the terrain in the YRB (Figures 1 and 2). Moreover, according to the scatter density plots of water samples (Figure S5), the study also observed that the MIWDR performed better for these water samples in the low-altitude YRB (Landsat path $<131$ ) than for these water samples in the high-altitude YRB (Landsat path $\geq 131$ ).

The extraction of open-surface water bodies was supported by the GEE cloud platform. Firstly, according to the quality band of Landsat surface reflectance products generated from the Fmask algorithm, cloud, cloud shadow, and snow were masked. It is noted that the Landsat 7 images after 2003 had the scan line errors. Therefore, these pixels with scan line errors also were masked. The unmasked pixels were regarded as good observations. Then according to the Landsat path, the suitable water detection rule was applied into each image to obtain a preliminary mapping of open-surface water bodies. Lastly, the study used the JRC global surface water occurrence layer to filter hill shadow and other misclassifications. All in all, the workflow of this study is shown in Figure 5.

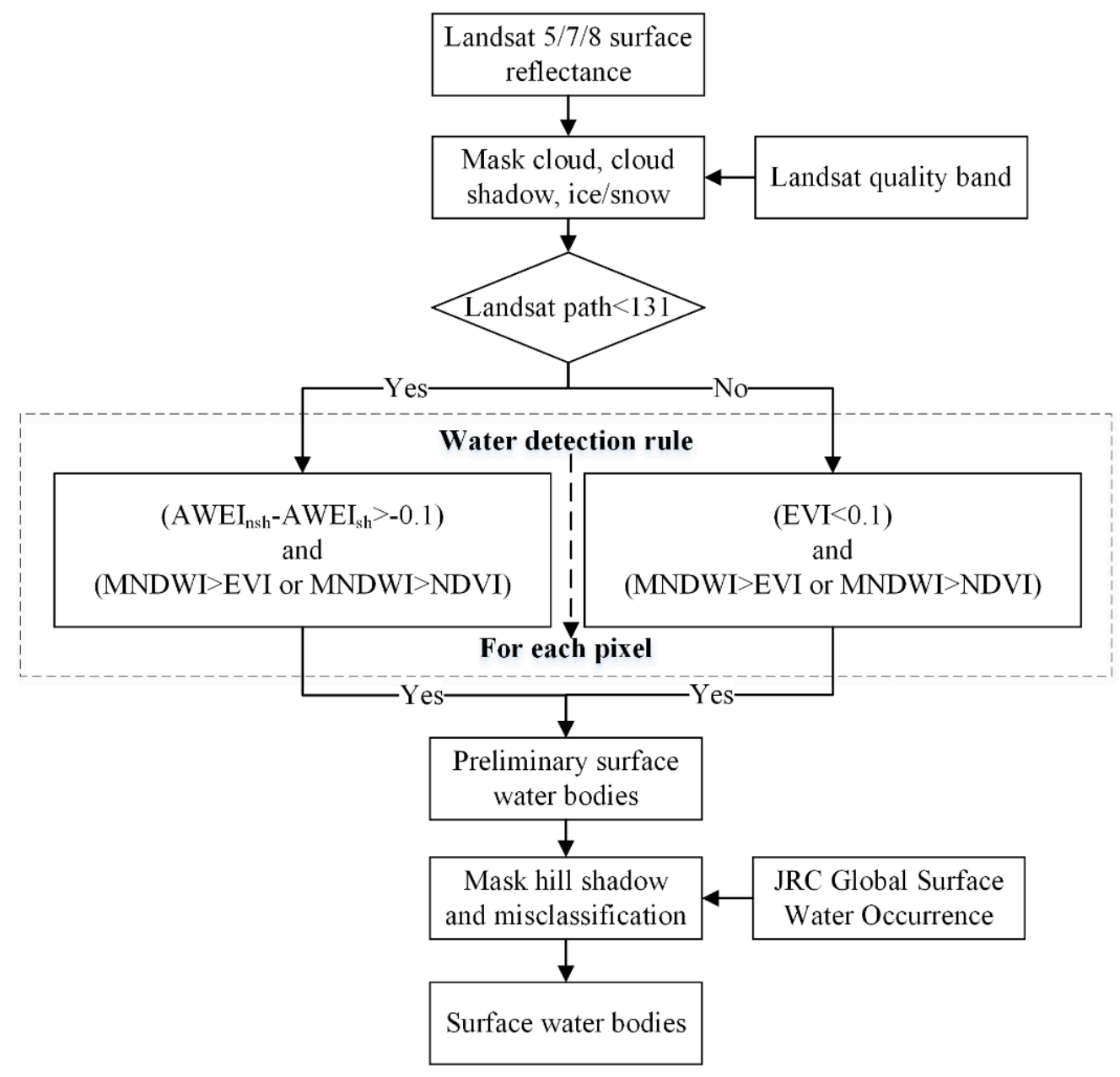

Figure 5. The flowchart of the extraction of surface water bodies in the Yangtze River Basin (YRB).

\subsubsection{Accuracy Assessment Based on Sentinel-2 Images}

This study used the Sentinel-2 images to evaluate the accuracy of the extracted open-surface water bodies in the YRB. Considering the strong dynamical variations in the extent of open-surface water bodies, the Landsat images and Sentinel images should have the same date, with a tolerance of no more than 2 days. Moreover, the cloud coverage of these images should be less than $15 \%$. Finally, a total of 24 Sentinel images were used (Table S1). In the 24 images, 9000 test samples, including 5424 water samples and 3576 non-water samples, were randomly generated within the extent of the extracted Landsat open-surface water bodies and another $60 \mathrm{~m}$ buffer which was created based on the boundary 
of the extracted Landsat open-surface water bodies. Finally, the study adopted a visual inspection to check the test samples.

\subsubsection{Change Analysis of an Open-Surface Water Body}

According to the long-term open-surface water bodies in the YRB, the water inundation frequency (WIF) of each pixel can be calculated from the following:

$$
\text { WIF }=\frac{\sum_{i=1}^{N} w}{N} \times 100 \%,
$$

where $N$ indicates the number of all the good observations in a specific period, and $w$ is a binary variable ( $\mathrm{w}=1$ indicates water body and $\mathrm{w}=0$ indicates non-water body). WIF ranges from $0 \%$ to $100 \%$. According to WIF, open-surface water bodies in the YRB can be divided into two types: permanent water bodies (WIF $>75 \%$ ) and seasonal water bodies $(25 \%<$ WIF $\leq 75 \%)[18,28]$.

Moreover, the maximum water bodies in one year were defined as the collection of the pixels with WIF $>0$. Here WIF was calculated for each year.

\section{Results}

\subsection{Accuracy of Extracted Open-Surface Water Bodies in the YRB}

Table 1 shows the accuracy of extracted open-surface water bodies in the YRB. The overall accuracy and kappa coefficient was $95.03 \%$ and 0.895 , respectively (Table 1), which indicated that the detected water products in the YRB had higher accuracy and then can be used for further analysis.

Table 1. The confusion matrix for accuracy assessment of this study.

\begin{tabular}{cccccc}
\hline \multirow{2}{*}{ Samples } & \multicolumn{2}{c}{ Sentinel } & \multirow{2}{*}{ Total } & \multirow{2}{*}{ User's Accuracy } \\
\cline { 3 - 4 } & Water & Non-Water & & \\
\hline \multirow{2}{*}{ Landsat } & Water body & 5302 & 122 & 5424 & $97.75 \%$ \\
& Non-water body & 325 & 3251 & 3576 & $90.91 \%$ \\
& 4627 & 3373 & 9000 & Overall accuracy $=95.03 \%$ \\
& Total & $94.22 \%$ & $96.38 \%$ & & Kappa coefficient $=0.895$ \\
\hline
\end{tabular}

\subsection{Spatial Distribution of the Open-Surface Water Bodies in the YRB}

The open-surface water bodies in the YRB showed a clearly uneven spatial distribution (Figure 6 and Table 2). About $49.99 \%$ of water bodies in the YRB were located in the MYRB, followed by $28.88 \%$ in the LYRB. A total of $13.25 \%$ and $7.87 \%$ of water bodies in the YRB were distributed in the UYRB and SYRB, respectively. In general, the areas of permanent water bodies and seasonal water bodies were $29,076.70 \mathrm{~km}^{2}$ and $21,526.24 \mathrm{~km}^{2}$, accounting for $57.46 \%$ and $42.54 \%$ of the total surface water bodies in YRB, respectively. The results indicated that the YRB was dominated by permanent water bodies. However, it can be observed that the LYRB had far more permanent water bodies than seasonal water bodies. The ratio of permanent water bodies to seasonal water bodies in the LYRB was 2.16, and the corresponding ratio for the SYRB, UYRB, and MYRB were 1.38, 1.21, and 1.06, respectively. 


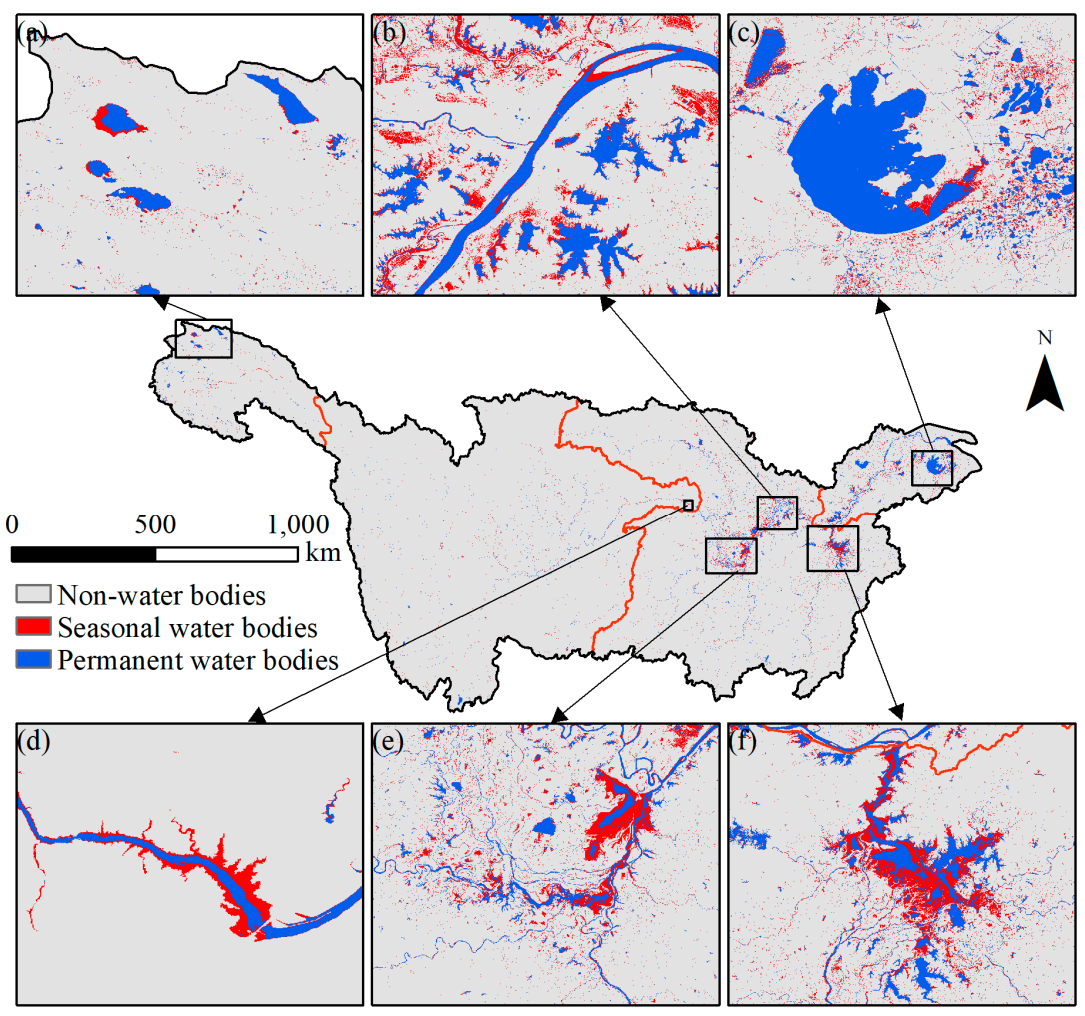

Figure 6. The spatial distribution of open-surface water bodies from 1984 to 2018 in the YRB. (a-f) indicates the source regions of the YRB, Wuhan city, Taihu Lake, the Three Gorges Dam (TGD), Dongting Lake, and Poyang Lake, respectively.

Table 2. The area of open-surface water bodies from 1984 to 2018 in the YRB.

\begin{tabular}{|c|c|c|c|}
\hline & $\begin{array}{c}\text { Seasonal Water Bodies } \\
\left(\mathbf{k m}^{2}\right)\end{array}$ & $\begin{array}{c}\text { Permanent Water Bodies } \\
\left(\mathrm{km}^{2}\right)\end{array}$ & Total \\
\hline SYRB & 1670.21 & 2315.82 & 3986.03 \\
\hline UYRB & 3023.91 & 3684.05 & 6707.96 \\
\hline MYRB & $12,221.84$ & $13,072.90$ & $25,294.73$ \\
\hline LYRB & 4610.28 & $10,003.93$ & $14,614.21$ \\
\hline YRB & $21,526.24$ & $29,076.70$ & $50,602.94$ \\
\hline
\end{tabular}

\subsection{Monthly Variations of the Surface Water Bodies in the YRB}

For each climatological month, the study also investigated the temporal dynamics of permanent and seasonal water bodies (Figure 7). The open-surface water bodies in the YRB showed a clear seasonality. The areas in wet months were obviously greater than those in dry months. Especially, the minimum extent of open-surface water bodies occurred in January, with a total area of 41,901.03 $\mathrm{km}^{2}$. The maximum extent of open-surface water bodies occurred in July, with a total area of 50,927.08 $\mathrm{km}^{2}$. If from the perspective of different four sub-basin, we can find similar characteristics of monthly variation (Figure S6). 


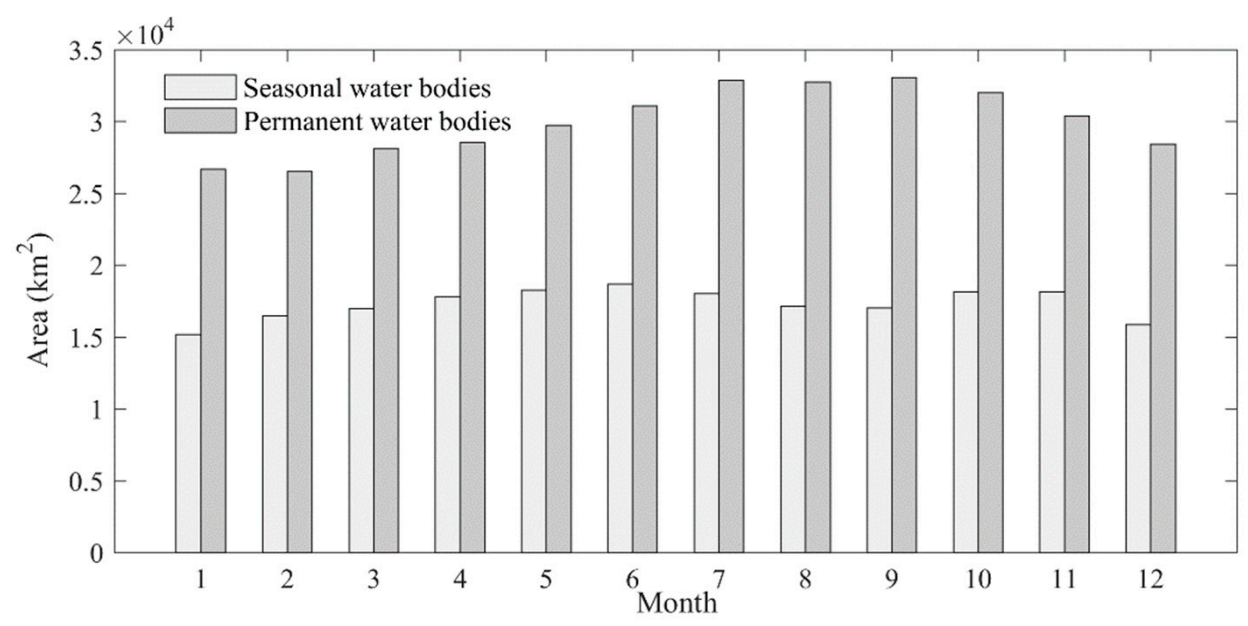

Figure 7. The monthly variation of surface water bodies for 1984 to 2018 in the YRB.

\subsection{Temporal Trends of the Open-Surface Water Bodies in the YRB}

In this part, we compared the open-surface water bodies in the YRB during three different periods: 1984-1999, 2000-2009, and 2010-2018 (Table 3). The maximum seasonal water bodies $\left(18,576.06 \mathrm{~km}^{2}\right)$ occurred during the period of 2000-2009, and the minimum seasonal water bodies $\left(16,427.70 \mathrm{~km}^{2}\right)$ appeared during the period of 2010-2018. Overall, the seasonal water bodies experienced a decreasing trend from 1984 to 2018, with a decreasing percentage of $8.68 \%$. However, the permanent water bodies in the YRB experienced an increasing trend, with an increasing percentage of $9.18 \%$. The areas of the permanent water bodies during the period of $1984-1999$ were $29,748.38 \mathrm{~km}^{2}$, and it increased to $30,654.89 \mathrm{~km}^{2}$ during the period of 2000-2009, and then increased to $32,479.51 \mathrm{~km}^{2}$. In general, the total open-surface water bodies in the YRB experienced an increasing trend from 1984 to 2018, with an increasing percentage of $2.45 \%$.

Table 3. The area of surface water bodies during different periods in the YRB.

\begin{tabular}{lcccc}
\hline \multirow{2}{*}{ Type } & \multicolumn{3}{c}{ Area $\left(\mathbf{k m}^{\mathbf{2}}\right)$} & Change Percentage (\%) \\
\cline { 2 - 5 } & $\mathbf{1 9 8 4 - 1 9 9 9}$ & $\mathbf{2 0 0 0 - 2 0 0 9}$ & $\mathbf{2 0 1 0 - 2 0 1 8}$ & $\mathbf{1 9 8 4 - 2 0 1 8}$ \\
\hline Seasonal water body & 17989.76 & 18576.06 & 16427.70 & $-8.68 \%$ \\
Permanent water body & 29748.38 & 30654.89 & 32479.51 & $9.18 \%$ \\
Total & 47738.15 & 49230.94 & 48907.22 & $2.45 \%$ \\
\hline
\end{tabular}

Moreover, we also investigated the temporal trends of open-surface water bodies in the four sub-basins (Figure 8). From 1984 to 2018, the seasonal water bodies in the SYRB had an increasing trend, while they showed a decreasing trend in the UYRB, MYRB, and LYRB. Especially, the MRYB experienced the most losses $\left(1192.42 \mathrm{~km}^{2}\right)$, followed by the UYRB $\left(279.83 \mathrm{~km}^{2}\right)$ and the LYRB $\left(119.13 \mathrm{~km}^{2}\right)$. When it comes to permanent water bodies, all the sub-basins revealed an increasing trend. The increased areas for the SYRB, UYRB, MYRB, and LRB were $594.15 \mathrm{~km}^{2}, 1144.25 \mathrm{~km}^{2}, 522.15 \mathrm{~km}^{2}$, and $471.79 \mathrm{~km}^{2}$, respectively. In general, the total open-surface water bodies in the SYRB, UYRB, and LYRB experienced an increasing trend, with an increasing percentage of $19.38 \%, 14.78 \%$, and $2.53 \%$. At the same time, the total open-surface water bodies in the MYRB suffered from a decreasing trend, with a decreasing percentage of $2.71 \%$. 

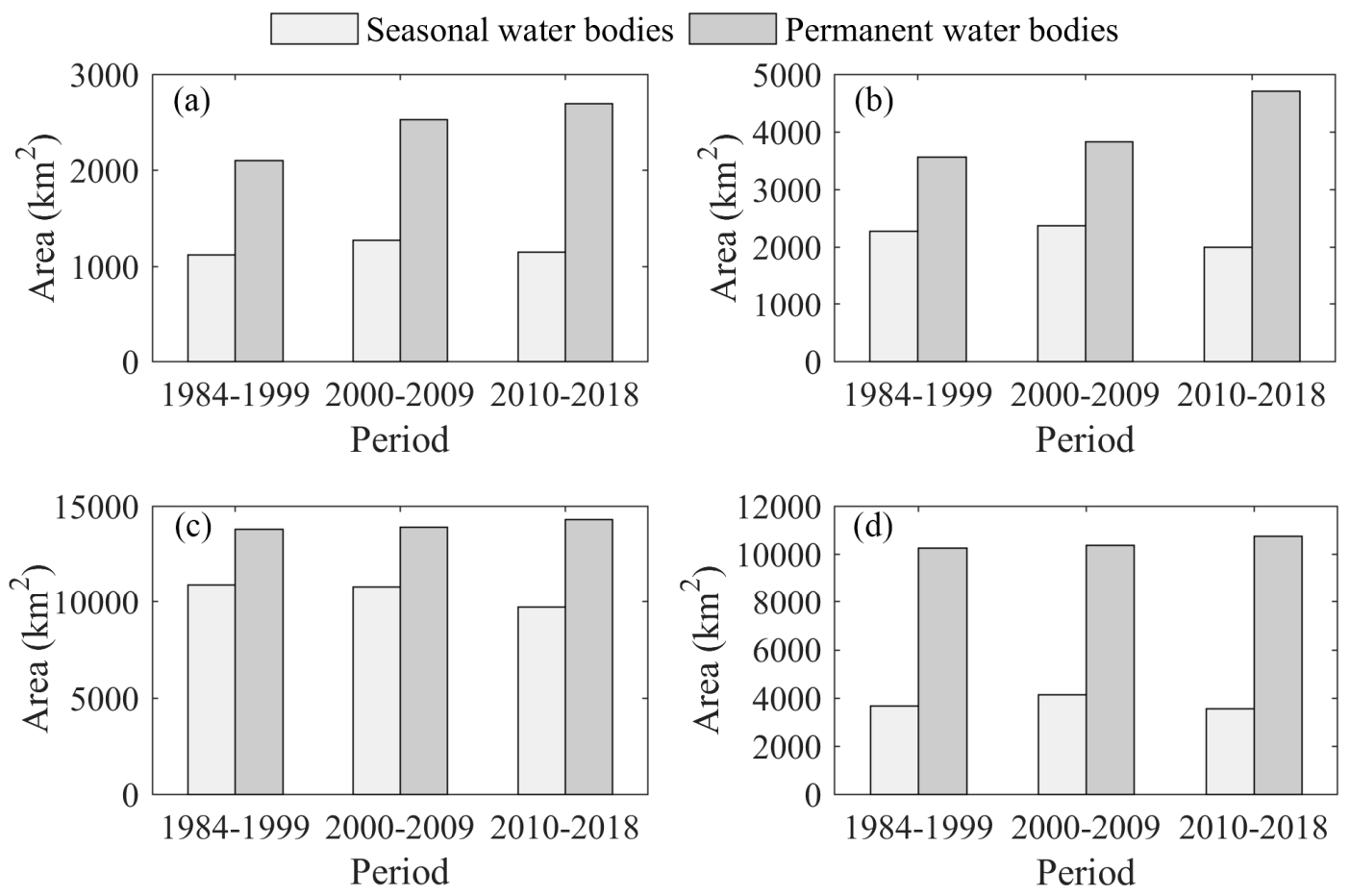

Figure 8. The area of open-surface water bodies during different periods in the (a) source of the YRB (SYRB), (b) the upper reaches of the YRB (UYRB), (c) the middle reaches of the YRB (MYRB), (d) and the lower reaches of the YRB (LYRB).

\subsection{Conversions of Open-Surface Water Bodies in the YRB}

Figure 9 further shows the conversion among non-water bodies, seasonal water bodies and permanent water bodies in the YRB. During the first two stages (1984-1999 and 2000-2009), the major increases in seasonal water bodies resulted from the conversion from non-water bodies with the conversion area of $4502.54 \mathrm{~km}^{2}$. Moreover, $2848.72 \mathrm{~km}^{2}$ permanent water bodies were converted into seasonal water bodies. At the same time, the major increases in permanent water bodies were caused by the conversion from seasonal water bodies with the conversion area of $2848.73 \mathrm{~km}^{2}$. Only $924.89 \mathrm{~km}^{2}$ non-water bodies were converted into permanent water bodies. During the last two phases (2000-2009 and 2010-2018), the most increases in permanent water bodies were still caused by the conversion from seasonal water bodies, with a conversion area of $4105.51 \mathrm{~km}^{2}$. However, the more seasonal water bodies $\left(4303.78 \mathrm{~km}^{2}\right)$ were converted into non-water bodies. A large amount of conversion in seasonal water bodies led to the decreases in the seasonal water bodies, though there were $6260.93 \mathrm{~km}^{2}$ new seasonal water bodies. Overall, from 1984 to 2018, the areas of new permanent water bodies were $7090.15 \mathrm{~km}^{2}$, and $59.87 \%$ of the increases in new permanent water bodies were caused by the conversion from seasonal water bodies. The areas of disappeared permanent water bodies were $4359.02 \mathrm{~km}^{2}$, and $77.01 \%$ of the decreases in permanent water bodies were converted into seasonal water bodies. Moreover, the areas of new seasonal water bodies were $8015.61 \mathrm{~km}^{2}$, and $58.09 \%$ of the increases in new seasonal water bodies resulted from the conversion from non-water bodies. The areas of disappeared seasonal water bodies were $9577.67 \mathrm{~km}^{2}$, and $55.68 \%$ of the decreases in seasonal water bodies were converted into non-water bodies. 


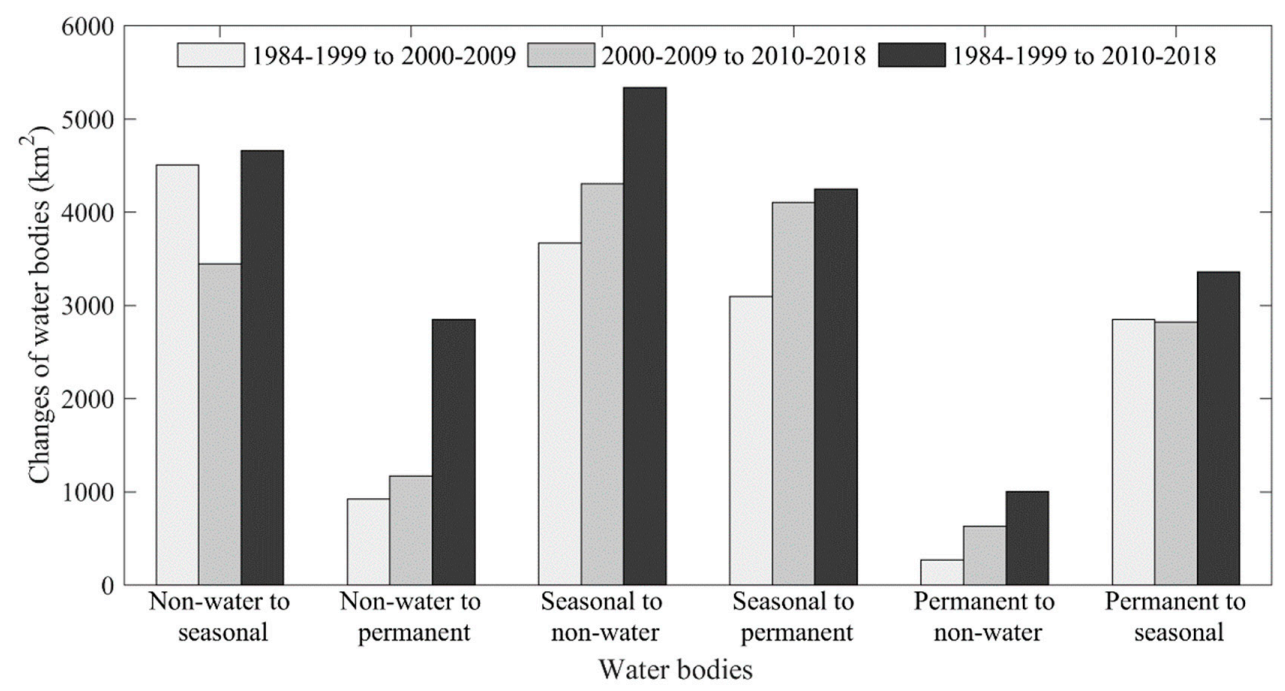

Figure 9. The conversion of open-surface water bodies in the YRB.

Furthermore, the study compared the conversions of open-surface water bodies in the four different sub-basins from 1984 to 2018 (Figures 10 and 11). In the SYRB, the conversion areas from non-water bodies to seasonal water bodies were $568.19 \mathrm{~km}^{2}$, and accounted for the largest proportion, while the conversion areas from permanent water bodies to seasonal water bodies were $122.28 \mathrm{~km}^{2}$, and took up the smallest proportion. In the UYRB, the conversion from non-water bodies to permanent water bodies was the most frequent, with the conversion areas of $867.21 \mathrm{~km}^{2}$. However, the conversion from permanent water bodies to non-water bodies was the least frequent, with the conversion areas of $88.33 \mathrm{~km}^{2}$. As for the MYRB, the conversion from permanent water bodies to non-water bodies still was the least frequent, with the conversion areas of $413.58 \mathrm{~km}^{2}$. However, the most frequent conversion was the conversion from seasonal water bodies to non-water bodies, with the conversion area of $3079.40 \mathrm{~km}^{2}$. When it comes to the LYRB, the conversion areas from non-water bodies to seasonal water bodies were $1461.24 \mathrm{~km}^{2}$, and accounted for the largest proportion, while the conversion areas from permanent water bodies to non-water bodies were $324.22 \mathrm{~km}^{2}$, and took up the smallest proportion. Overall, the conversions of open-surface water bodies in the YRB revealed the obvious spatial heterogeneity.

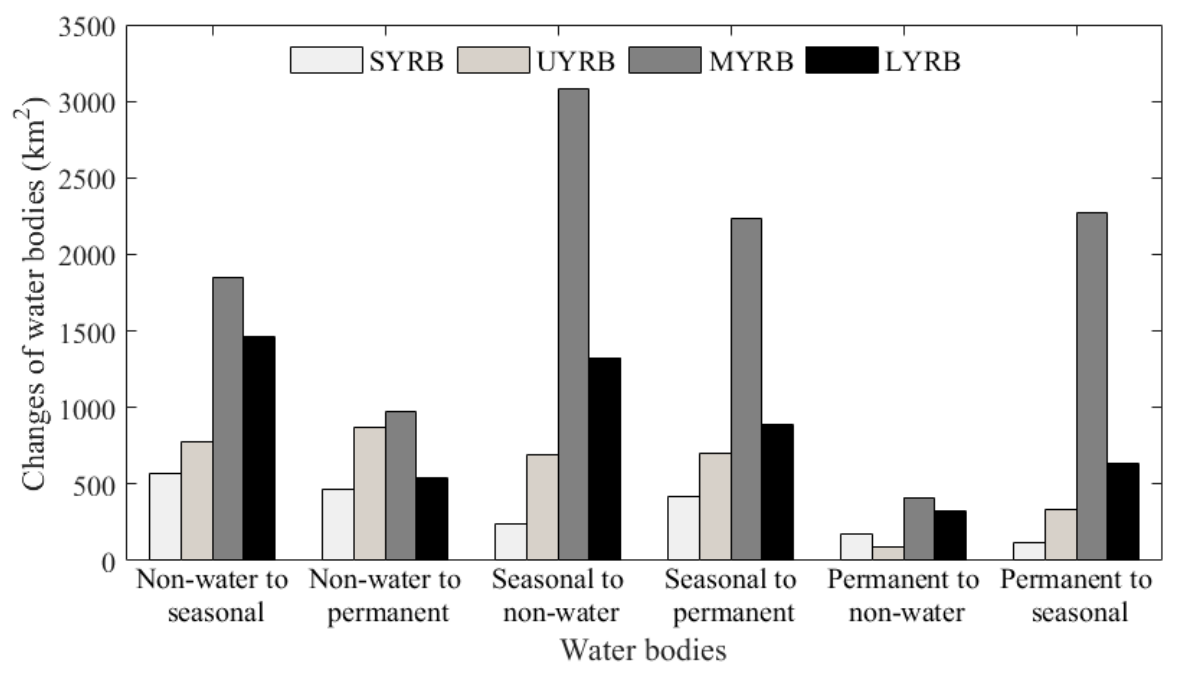

Figure 10. The conversion of surface water bodies from 1984 to 2018 for the sub-basins in the YRB. 


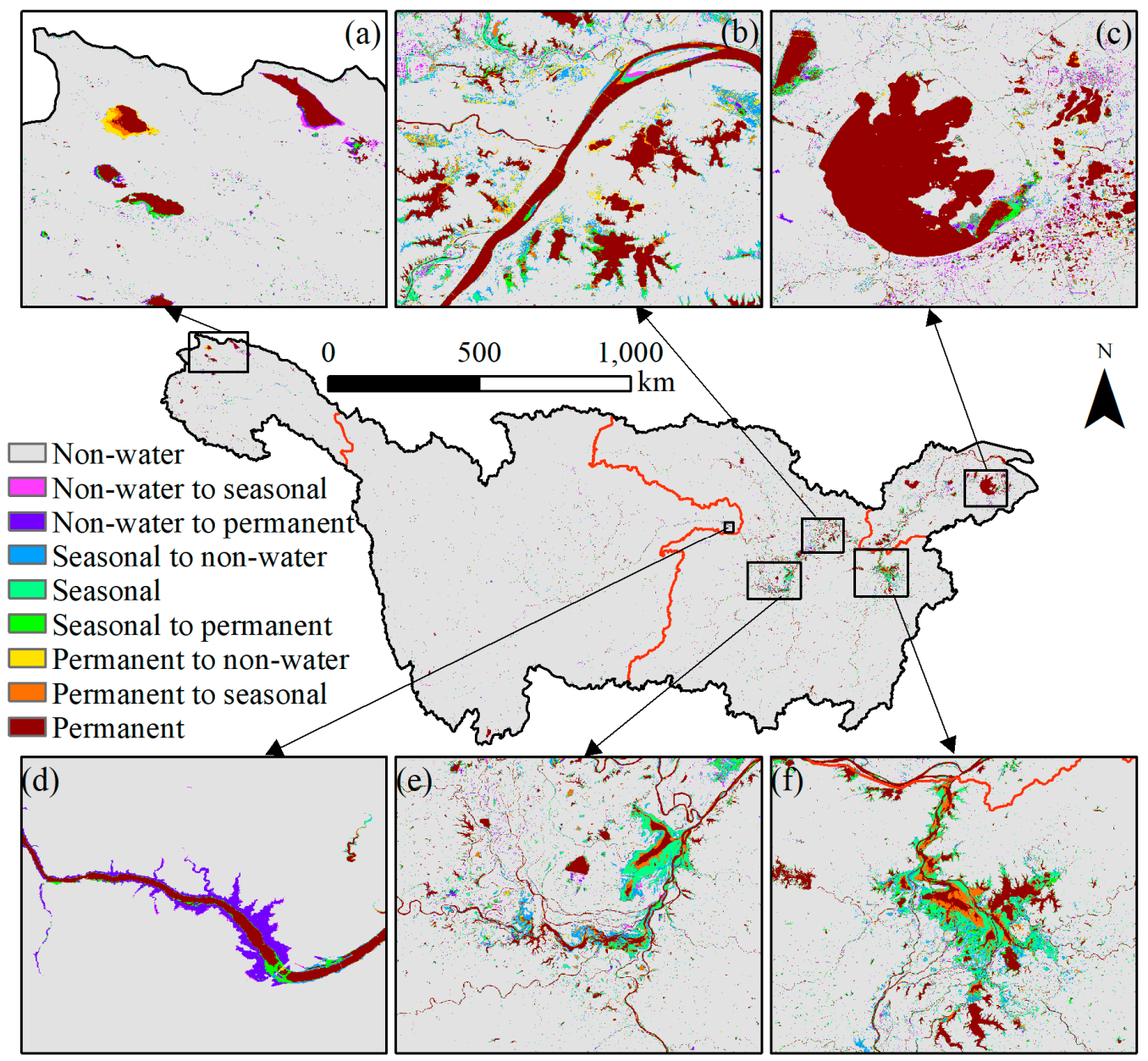

Figure 11. The spatial pattern of conversion of surface water bodies from 1984 to 2018 in the YRB. (a-f) indicates the source regions of the YRB, Wuhan city, Taihu Lake, the Three Gorges Dam (TGD), Dongting Lake and Poyang Lake, respectively.

\subsection{The Changes of Yearly Maximum Water Bodies and their Relationship with Precipitations in the YRB}

Figure 12 shows the time series of yearly maximum surface water bodies and annual precipitation in the YRB from 1984 to 2018. Moreover, the study estimated the temporal trends of maximum water bodies and annual precipitation, and calculated the correlation coefficient between them (Table 4). During the period of 1984-1999, the maximum water bodies showed the increasing trend, though the trend was not significant $(P$-value $=0.126)$. At the same time, the precipitation also showed a significantly increasing trend at the significance level of $0.1(P$-value $=0.052)$. During this period, the correlation coefficient between the area and precipitation was $0.635(P$-value $=0.019)$. Moreover, the study observed the largest area of maximum water bodies occurred in 1998, when the annual precipitation reached the peak in this period. During the period of 2000-2009, the maximum water bodies and annual precipitation exhibited the decreasing trend. Especially, the trend for the former was significant at the significance level of $0.1(P$-value $=0.092)$. In this period, the correlation coefficient decreased to 0.569 ( $P$-value $=0.086)$. In this period, the peak of maximum water bodies and precipitation appeared in 2002. During the period of 2010-2018, the maximum water bodies and annual precipitation kept a slightly increasing trend. In this period, the correlation coefficient further decreased to 0.221 $(P$-value $=0.568)$. In this period, the peak of maximum water bodies and precipitation occurred simultaneously in 2010 and 2016. 


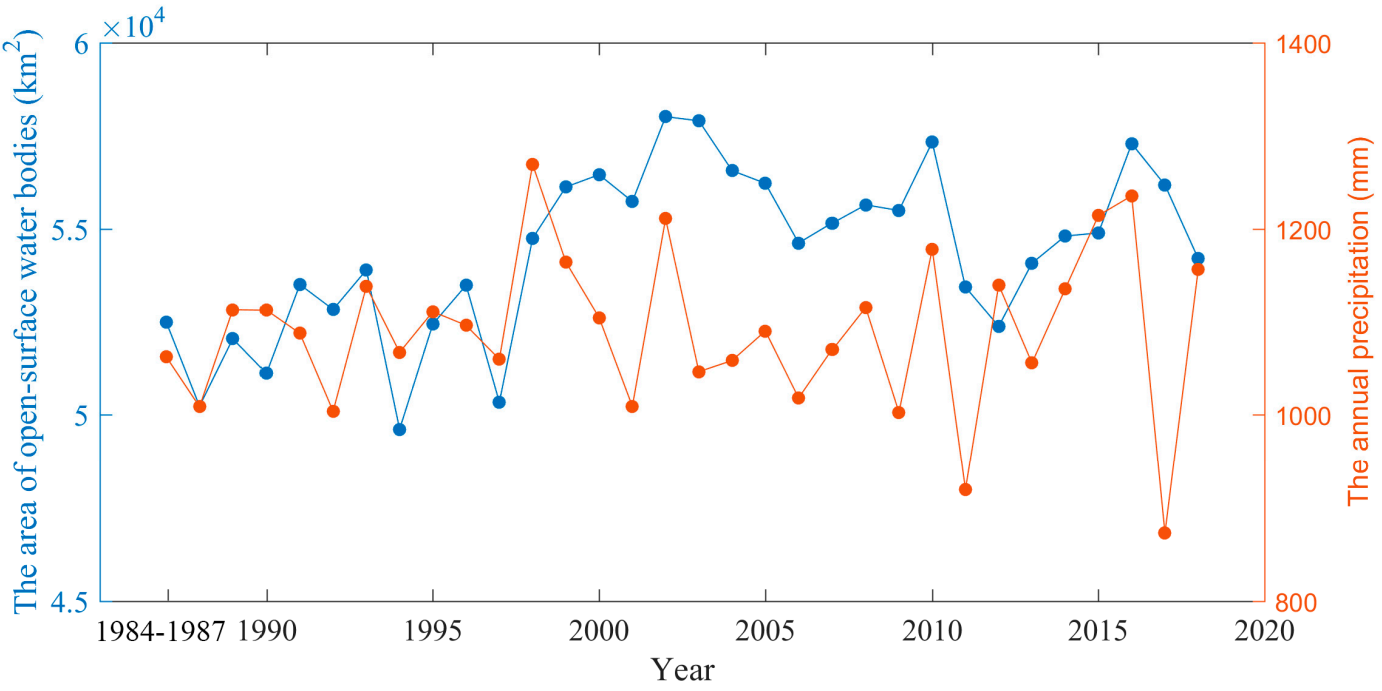

Figure 12. The time series of maximum water bodies and annual precipitation in the YRB from 1984 to 2018.

Table 4. The trend and correlation in maximum water bodies and precipitation in the YRB.

\begin{tabular}{llll}
\hline Period & Maximum water bodies & Precipitation & Correlation \\
\hline \multirow{2}{*}{ 1984-1999 } & $y=215.74 x+51018 ;$ & $y=9.6832 x+1031.8 ;$ & $\mathrm{R}^{2}=0.635 ;$ \\
& $\mathrm{R}^{2}=0.199, P$-value $=0.126$ & $\mathrm{R}^{2}=0.302 ; P$-value $=0.052$ & $P$-value $=0.019$ \\
& $y=-204.78 x+57307 ;$ & $y=-5.6389 x+1103.6 ;$ & $\mathrm{R}^{2}=0.569 ;$ \\
& $\mathrm{R}^{2}=0.314 ; P$-value $=0.092$ & $\mathrm{R}^{2}=0.075 ; P$-value $=0.445$ & $P$-value $=0.086$ \\
2010-2018 & $y=105.74 x+54425 ;$ & $y=2.036 x+1090.6 ;$ & $\mathrm{R}^{2}=0.221 ;$ \\
2010-2018 & $\mathrm{R}^{2}=0.029 ; P$-value $=0.659$ & $\mathrm{R}^{2}=0.002 ; P$-value $=0.911$ & $P$-value $=0.568$ \\
(excluding 2012) & $y=20361 x ;$ & $y=2.7481 x+1083.5 ;$ & $\mathrm{R}^{2}=0.351 ;$ \\
2000-2018 & $\mathrm{R}^{2}=0.000 ; P$-value $=0.964$ & $\mathrm{R}^{2}=0.003 ; P$-value $=0.853$ & $P$-value $=0.394$ \\
2000-2018 & $y=-128187 x ;$ & $y=0.5296 x+1077 ;$ & $\mathrm{R}^{2}=0.217 ;$ \\
(excluding 2012) & $\mathrm{R}^{2}=0.185 ; P$-value $=0.066$ & $\mathrm{R}^{2}=0.001 ; P$-value $=0.702$ & $P$-value $=0.372$ \\
1984-2018 & $y=-103876 x ;$ & $y=1.1993 x+1071.5 ;$ & $\mathrm{R}^{2}=0.338 ;$ \\
& $\mathrm{R}^{2}=0.130 ; P$-value $=0.077$ & $\mathrm{R}^{2}=0.004 ; P$-value $=0.758$ & $P$-value $=0.171$ \\
& $y=129.31 x+52218 ;$ & $y=0.3669 x+1085.4 ;$ & $\mathrm{R}^{2}=0.207 ;$ \\
& $\mathrm{R}^{2}=0.292 ; P$-value $=0.001$ & $\mathrm{R}^{2}=0.002 ; P$-value $=0.827$ & $P$-value $=0.256$ \\
\hline
\end{tabular}

\section{Discussion}

\subsection{Changes in Open-Surface Water Bodies due to Climate and Human Factors}

The maximum-water bodies had a good correlation with annual precipitation, especially in the period of 1984-1999 and 2000-2010. The results indicated the precipitation was the important factor that controls the open-surface water bodies in the YRB. Moreover, for the whole YRB, the precipitation showed a slightly increasing trend from 1984 to 2018 (Table 4). More precipitation suggested that there were more chances for the conversions form non-water bodies/seasonal water bodies to permanent water bodies. Therefore, the permanent water bodies in the YRB increased along with the decreases in the seasonal water bodies from 1984 to 2018. However, the precipitation trend varied much in the YRB (Figure 13). The SYRB and LYRB experienced the increasing precipitation, which suggested the water bodies increased. However, the MYRB suffered from the decreasing precipitation, especially in the Dongting Lake Basin, which indicated the water bodies decreased (Figure S7). Moreover, there is no doubt that precipitation was not the only climate factor. For example, many studies have indicated that the increasing glacier meltwater has led to the expansion of the lakes in the Tibetan Plateau (including the SYRB) due to the warming temperature [50-52]. Therefore, both the seasonal water bodies and permanent water bodies in the SYRB increased from 1984 to 2018. 


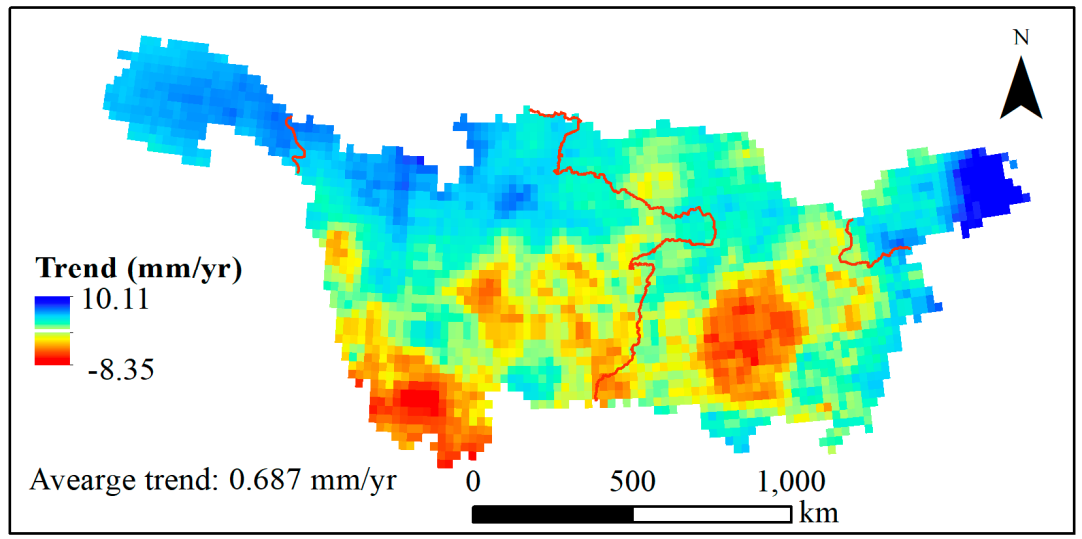

Figure 13. The spatial pattern of the trend of annual precipitation from 1984 to 2018 in the YRB. The magnitude of trends was evaluated by a linear regression model.

In this study, we observed that the correlation coefficient between maximum water bodies and annual precipitation decreased from 1984 to 2018. The possible reason was the fact that the influence of human activities in the YRB has increased over the past years. Many studies have demonstrated the influence of human activities on the surface water bodies [37,53,54]. YRB experienced intense human activities over the past years, which led to a complicated influence on the surface water bodies. On the one hand, the surface water bodies were encroached on by other land use types because of urban expansion, agricultural production, and so on. For instance, Deng et al. [55] found the urban expansions caused the decrease in the lake area in the Wuhan urban agglomeration. The negative impacts of human activities on the surface water bodies were clearly observed in Wuhan city, in the MYRB (Figure 14). Whereas, on the other hand, human activities can also contribute to more surface water bodies. For example, in the UYRB, the permanent water bodies experienced substantial increases. One important factor was the Three Gorges Dam (TGD). We compared the surface water bodies in the Three Gorges Reservoir Area before (1984-2002) and after (2003-2018) the TGD and found the permanent water bodies increased by $307.33 \mathrm{~km}^{2}$, which demonstrated the huge influences of human activities on the increases of surface water bodies in the UYRB (Figure 15). Moreover, with more and more attention to water protection for key lakes and reservoirs from China during the recent ten years, the water bodies were expected to increase [18].

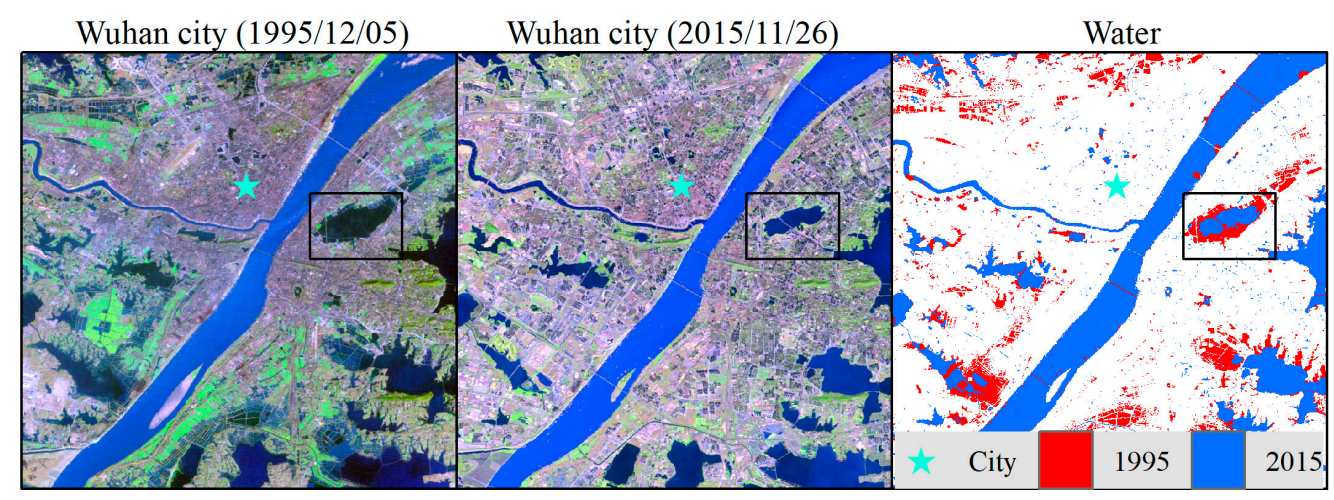

Figure 14. The losses in water bodies due to urban expansions in Wuhan city. 

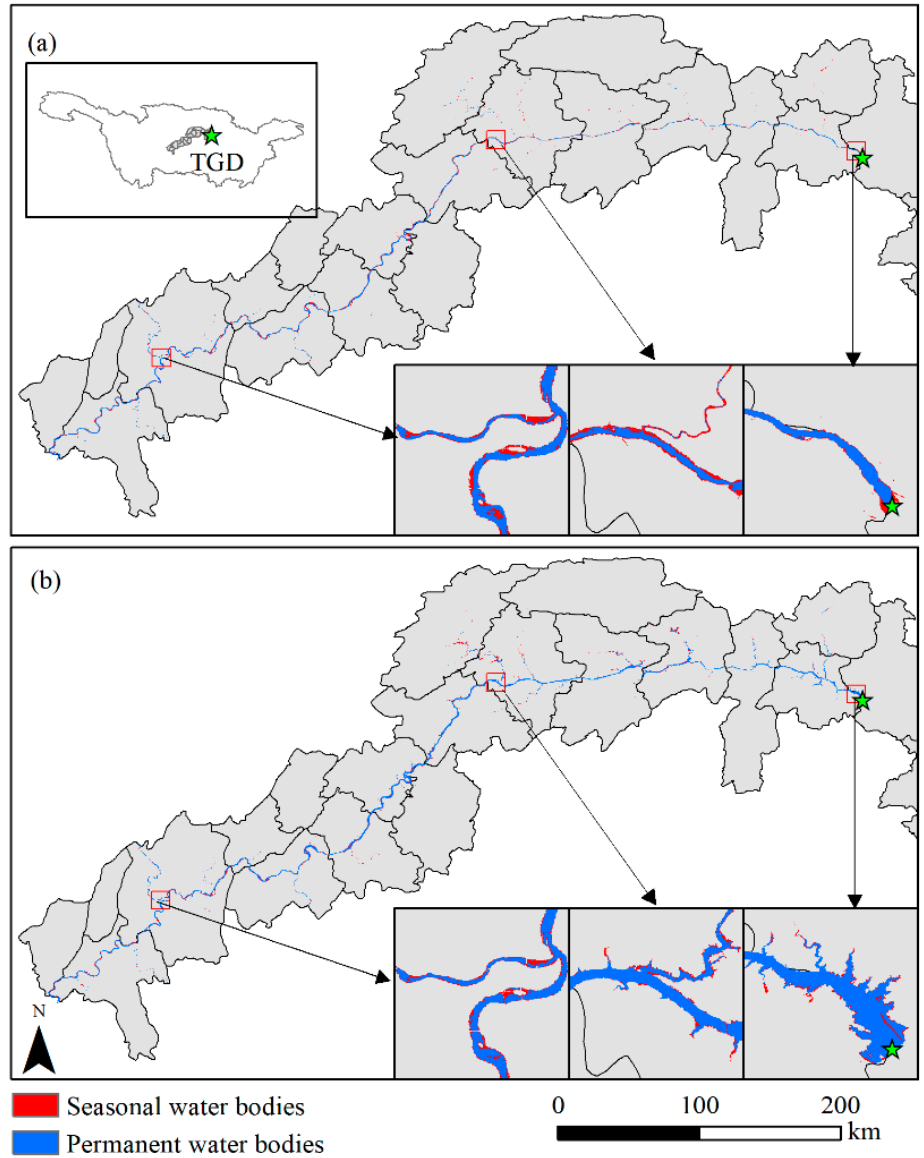

Figure 15. Open-surface water bodies (a) before (1984-2002) and (b) after (2003-2018) the TGD.

This study did not examine more detailed reasons for the long-term changes of open-surface water bodies in the YRB. In the next work, we will focus on the important regions, including two large lakes (Dongting Lake and Poyang Lake) and Wuhan urban agglomeration. We will investigate the changes and explore reasons by using more economic and social data.

\subsection{Long-Term and Large-Scale Mapping of Open-Surface Water Bodies by GEE Platform}

For the long-term and large-scale classification study, the collection of samples is a primary work. The samples should contain different years, seasons, and regions to reduce the possible sample bias. For this purpose, previous studies often chose the images and collected the samples from different years, seasons, and regions. For example, Zou et al. [28] collected the training samples from the 16 sampling plots of different years and regions. However, for each sampling plot, it just contains one year. Therefore, possible sample bias would occur. Moreover, this process is also relatively time-consuming. In this study, with the help of the high performance on the image processing in the GEE platform, we used the cloud-free percentile composite images as the sampling plot and collected the water and non-water samples from the sampling plot. This process is easy to operate in the GEE and can obtain more representative samples. We also thought the cloud-free percentile composite images can be used to collect samples for classifying other land-use types.

Moreover, this study proposed a new water detection rule called MIWDR based on the existed vegetation indices (NDVI and EVI) and water indices ( $A W E I_{\text {nsh }}$ and $\mathrm{AWEI}_{\text {sh }}$ ). Compared with the water detection rule proposed by Zou et al. [28], the MIWDR in the study can alleviate effectively the impacts of urban building, although it leads to some narrow urban rivers were misclassified. However, we thought the MIWDR is suitable for long-term and large-scale water bodies mapping in the urban regions with a lower threshold for the condition (AWEI $\left.I_{\text {shh }}-\mathrm{AWEI}_{\text {sh }}\right)$ (Figure 16). The MIWDR had 
relatively low accuracy for these water bodies in the plateau region of the YRB (Figure S3). Therefore, the study adopted a strategy using the different methods to extract water bodies from different areas in the YRB. In conclusion, for the long-term mapping of surface water bodies at more large scale, such as continent-scale, even global scale, the situation will be more complicated, there is still much work to do.
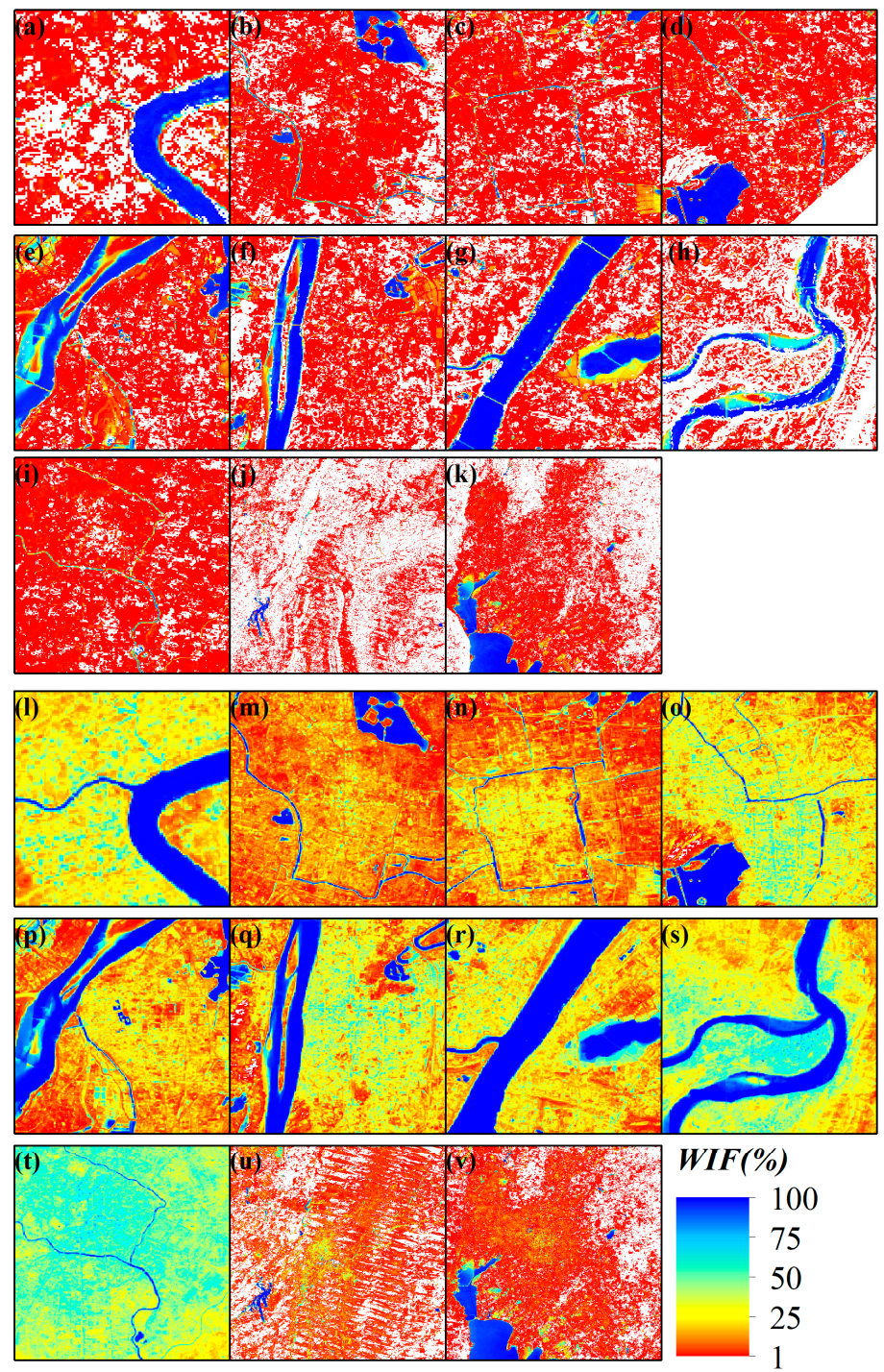

Figure 16. Comparisons of the water identification rule of this study and Zou et al. [28] in urban regions. (a-k) indicates the extracted water bodies according to the method of this study in Shanghai, Nanjing, Suzhou, Hangzhou, Nanchang, Changsha, Wuhan, Chongqing, Chengdu, Guizhou, and Kunming, respectively. (i-v) indicates the resulsts according to the method of Zou et al. [28] in the same cities with (a-k).

\subsection{Uncertainty and Prospects}

This study explored the spatiotemporal changes of open-surface water bodies in the YRB from 1984-2018 using all the available Landsat images. However, the number of image showed the remarkable spatial and temporal variations in the YRB, which resulted in a negative influence on the study results. The number of Landsat images during the period of 1984-1999, 2000-2009, and 2010-2018 were $18,437,29,696$, and 27,460, respectively. The total number during the first period was much less than that during the following two periods. Therefore, we observed that the areas of maximum water bodies during the first period were far lower than those for the latter two periods. In 2012, Landsat 5 
terminated, so the number of images in 2012 decreased. We calculated the correlation coefficient between maximum water bodies and annual precipitation under two scenarios: one included the images of 2012 and another did not include the images of 2012 (Table 4). The comparison between two scenarios indicated the correlation coefficient increased without the images of 2012. The quantitative results further demonstrated the influence of the number of images.

Moreover, we also investigated the changes in water bodies in the YRB from 1984 to 2018 based on the concept of WIF. Firstly, from the perspective of monthly variations, the amount of Landsat images from May to September is the least, while the area of open-surface water bodies was still the largest. These results indicated the monthly variations of open-surface water bodies in the YRB was reliable since the precipitations from May to October are estimated to be about $70 \%-90 \%$ of the annual total precipitation in the YRB [43]. Regarding the temporal trends, the study found the decreasing lake areas in Poyang Lake and Dongting Lake (Figure S7) from 1984 to 2018, which was in line with previous studies [18,54]. The reasonable reason is the fact that the total number of images during each month is enough to obtain a relatively reliable WIF. However, the temporal changes of open-surface water bodies in the YRB from 1984 to 2018 still showed the uncertainty, especially for the region with fewer images.

Furthermore, we compared the spatial pattern of permanent and seasonal water bodies of this study and the JRC water product (Figure 17). In general, the two products have a similar spatial pattern. The total permanent water bodies in the YRB based on JRC product were $30,610.79 \mathrm{~km}^{2}$, which was $1534.09 \mathrm{~km}^{2}$ more than this study. The total seasonal water bodies in the YRB based on JRC product were $27,007.51 \mathrm{~km}^{2}$, which was $5481.27 .09 \mathrm{~km}^{2}$ more than this study. The reason is that the WIF of JRC product was manually adjusted, therefore the WIF of some pixels was larger than those of this study. Therefore, using the same threshold (25\% and $75 \%)$ to classify the water bodies in the YRB would result in more water bodies than this study.

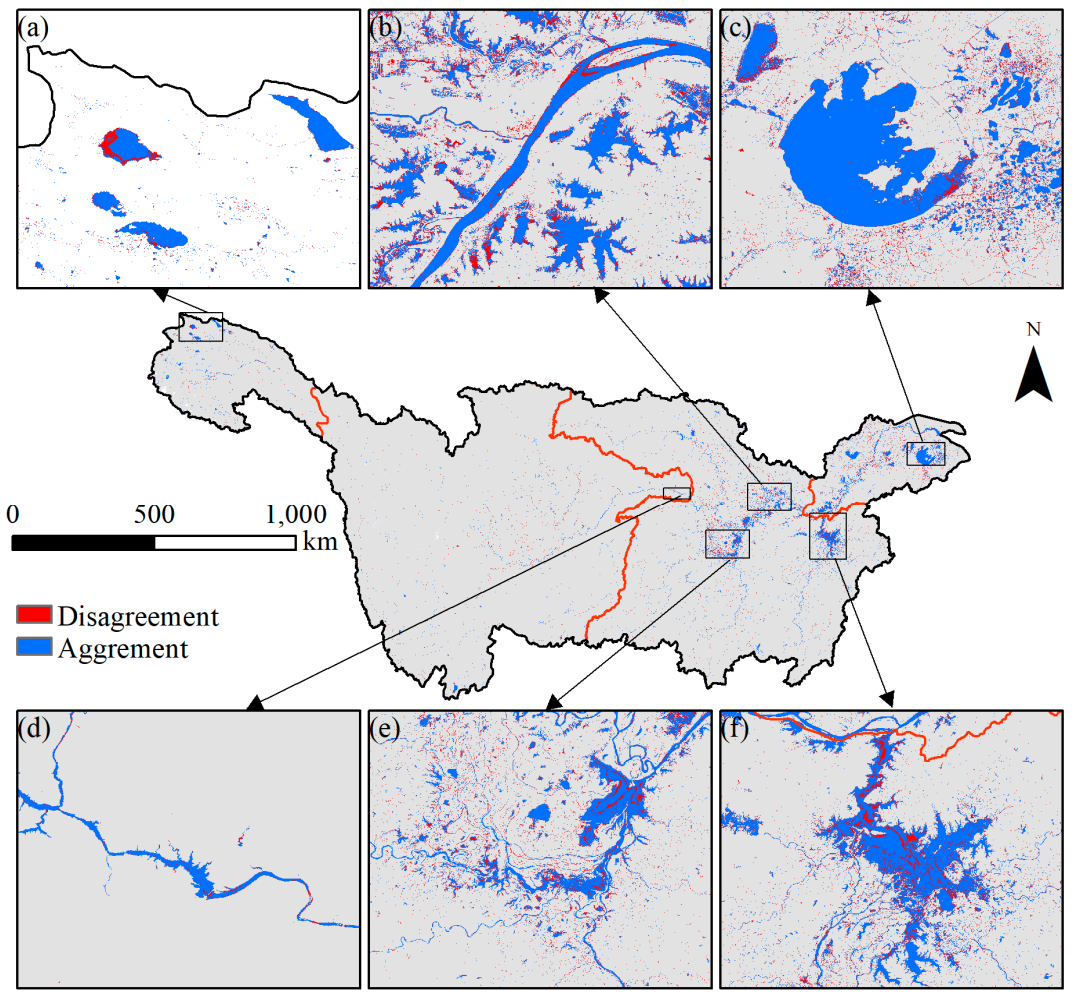

Figure 17. Comparisons of the spatial pattern of permanent and seasonal water bodies of this study and JRC water product. "Agreement" indicated both the water mapping have the same water type. In contrast, "Disagreement" indicated the two water mapping having different water types. (a-f) indicates the source regions of the YRB, Wuhan city, Taihu Lake, the Three Gorges Dam (TGD), Dongting Lake and Poyang Lake, respectively. 
GEE platform provided fast access to MODIS, Landsat, and Sentinel images. Merging the multi-source remote sensing data to investigate the changes of open-surface water bodies in the GEE platform can efficiently reduce the uncertainty, and it is also a hot topic.

\section{Conclusions}

In this study, a framework for long-term mapping of open-surface water bodies in the GEE platform was proposed. It includes a percentile-based image composite method to collect the training samples and a new water detection rule called MIWDR to quickly extract the open-surface water bodies. The percentile-based image composite method can obtain more representative samples for a classification model and can be used to map other land-use types. The MIWDR is based on the existing water index and vegetation index, and is suitable for the mapping of the long-term and large-scale Landsat water bodies in the urban regions.

The study investigated the long-term changes of open-surface water bodies in the YRB from 1984 to 2018 based on all available Landsat 5/7/8 images in the GEE platform. The open surface water bodies were classified into permanent water bodies and seasonal water bodies according to the inundation frequency. The YRB was dominated by the permanent water bodies, especially in the LYRB. With the increasing precipitation and intense human activities, the permanent water bodies in the YRB increased along with the decreases in the seasonal water bodies from 1984 to 2018 . However, the long-term changes of open-surface water bodies in the YRB revealed the obvious spatial heterogeneity. For the permanent water bodies, all the sub-basins (SYRB, UYRB, MYRB, and LYRB) revealed an increasing trend, especially for SYRB and UYRB. Whereas, when it comes to seasonal water bodies, SYRB had an increasing trend, while UYRB, MYRB, and LYRB showed a decreasing trend. Moreover, the most frequent conversion was different among the SYRB (from non-water bodies to seasonal water bodies), UYRB (from non-water bodies to permanent water bodies), MYRB (from seasonal water bodies to non-water bodies), and LYRB (from non-water bodies to seasonal water bodies).

Supplementary Materials: The following are available online at http://www.mdpi.com/2072-4292/11/19/2213/s1, Figure S1: Spatial distribution of the average annual precipitation in the YRB. Figure S2: Comparisons of the water detection rule of this study and Zou et al. [28] in the non-urban regions. Figure S3: Comparisons of the water detection rule of this study and Zou et al. [28] in the urban regions. Figure S4: Comparisons of the water detection rule of this study and Zou et al. [28] in the plateau region. Figure S5: The scatter density of water samples. (a) and (b) indicates the water samples from the sampling plots with Landsat path $\geq 131$. (c) and (d) indicates the water samples from the sampling plot with Landsat path $<131$. Table S1: The Landsat and Sentinel image for accuracy assessment. Figure S6: The monthly variation of open-surface water bodies for 1984 to 2018 in the (a) SYRB, (b) UYRB, (c) MYRB, and (d) LYRB. Figure S7: The changes of lake area in Poyang Lake and Dongting Lake.

Author Contributions: Conceptualization, Y.D. and W.J.; methodology, Y.D. and Z.T.; Writing一original draft, Y.D.; writing-review and editing, Z.T., Z.L., and Z.W.

Funding: This research was funded by the National Key R\&D Program of China [2016YFC0503002], and by the National Natural Science Foundation of China under Grant [41571077].

Acknowledgments: We gratefully acknowledge the China Scholar Council.

Conflicts of Interest: The authors declare no conflict of interest.

\section{References}

1. Costanza, R.; d'Arge, R.; De Groot, R.; Farber, S.; Grasso, M.; Hannon, B.; Limburg, K.; Naeem, S.; O’Neill, R.V.; Paruelo, J.; et al. The value of the world's ecosystem services and natural capital. Nature 1997, $387,253$. [CrossRef]

2. Wood, E.F.; Roundy, J.K.; Troy, T.J.; van Beek, L.P.H.; Bierkens, M.F.P.; Blyth, E.; de Roo, A.; Döll, P.; Ek, M.; Famiglietti, J.; et al. Hyperresolution global land surface modeling: Meeting a grand challenge for monitoring Earth's terrestrial water. Water Resour. Res. 2011, 47. [CrossRef]

3. Pekel, J.-F.; Cottam, A.; Gorelick, N.; Belward, A.S. High-resolution mapping of global surface water and its long-term changes. Nature 2016, 540, 418-422. [CrossRef] [PubMed]

4. Jiang, Y. China's water scarcity. J. Environ. Manag. 2009, 90, 3185-3196. [CrossRef] [PubMed] 
5. Khandelwal, A.; Karpatne, A.; Marlier, M.E.; Kim, J.; Lettenmaier, D.P.; Kumar, V. An approach for global monitoring of surface water extent variations in reservoirs using MODIS data. Remote Sens. Environ. 2017, 202, 113-128. [CrossRef]

6. Li, L.; Vrieling, A.; Skidmore, A.; Wang, T.; Turak, E. Monitoring the dynamics of surface water fraction from MODIS time series in a Mediterranean environment. Int. J. Appl. Earth Obs. Geoinf. 2018, 66, 135-145. [CrossRef]

7. Lu, S.; Jia, L.; Zhang, L.; Wei, Y.; Baig, M.H.A.; Zhai, Z.; Meng, J.; Li, X.; Zhang, G. Lake water surface mapping in the Tibetan Plateau using the MODIS MOD09Q1 product. Remote Sens. Lett. 2017, 8, 224-233. [CrossRef]

8. Ranghetti, L.; Busetto, L.; Crema, A.; Fasola, M.; Cardarelli, E.; Boschetti, M. Testing estimation of water surface in Italian rice district from MODIS satellite data. Int. J. Appl. Earth Obs. Geoinf. 2016, 52, $284-295$. [CrossRef]

9. Zhang, Y.; Shi, K.; Zhou, Y.; Liu, X.; Qin, B. Monitoring the river plume induced by heavy rainfall events in large, shallow, Lake Taihu using MODIS 250m imagery. Remote Sens. Environ. 2016, 173, 109-121. [CrossRef]

10. Che, X.; Feng, M.; Sexton, J.; Channan, S.; Sun, Q.; Ying, Q.; Liu, J.; Wang, Y. Landsat-Based Estimation of Seasonal Water Cover and Change in Arid and Semi-Arid Central Asia (2000-2015). Remote Sens. 2019, 11, 1323. [CrossRef]

11. Jia, K.; Jiang, W.; Li, J.; Tang, Z. Spectral matching based on discrete particle swarm optimization: A new method for terrestrial water body extraction using multi-temporal Landsat 8 images. Remote Sens. Environ. 2018, 209, 1-18. [CrossRef]

12. Li, L.; Chen, Y.; Xu, T.; Liu, R.; Shi, K.; Huang, C. Super-resolution mapping of wetland inundation from remote sensing imagery based on integration of back-propagation neural network and genetic algorithm. Remote Sens. Environ. 2015, 164, 142-154. [CrossRef]

13. Tulbure, M.G.; Broich, M. Spatiotemporal patterns and effects of climate and land use on surface water extent dynamics in a dryland region with three decades of Landsat satellite data. Sci. Total Environ. 2019, 658, 1574-1585. [CrossRef] [PubMed]

14. Wang, X.; Xie, S.; Zhang, X.; Chen, C.; Guo, H.; Du, J.; Duan, Z. A robust Multi-Band Water Index (MBWI) for automated extraction of surface water from Landsat 8 OLI imagery. Int. J. Appl. Earth Obs. Geoinf. 2018, 68, 73-91. [CrossRef]

15. Hardy, A.; Ettritch, G.; Cross, D.E.; Bunting, P.; Liywalii, F.; Sakala, J.; Silumesii, A.; Singini, D.; Smith, M.; Willis, T.; et al. Automatic Detection of Open and Vegetated Water Bodies Using Sentinel 1 to Map African Malaria Vector Mosquito Breeding Habitats. Remote Sens. 2019, 11, 593. [CrossRef]

16. Schwatke, C.; Scherer, D.; Dettmering, D. Automated Extraction of Consistent Time-Variable Water Surfaces of Lakes and Reservoirs Based on Landsat and Sentinel-2. Remote Sens. 2019, 11, 1010. [CrossRef]

17. Steinhausen, M.J.; Wagner, P.D.; Narasimhan, B.; Waske, B. Combining Sentinel-1 and Sentinel-2 data for improved land use and land cover mapping of monsoon regions. Int. J. Appl. Earth Obs. Geoinf. 2018, 73, 595-604. [CrossRef]

18. Wang, C.; Jia, M.; Chen, N.; Wang, W. Long-Term Surface Water Dynamics Analysis Based on Landsat Imagery and the Google Earth Engine Platform: A Case Study in the Middle Yangtze River Basin. Remote Sens. 2018, 10, 1635. [CrossRef]

19. Gorelick, N.; Hancher, M.; Dixon, M.; Ilyushchenko, S.; Thau, D.; Moore, R. Google Earth Engine: Planetary-scale geospatial analysis for everyone. Remote Sens. Environ. 2017, 202, 18-27. [CrossRef]

20. Mutanga, O.; Kumar, L. Google Earth Engine Applications. Remote Sens. 2019, 11, 591. [CrossRef]

21. Oliphant, A.J.; Thenkabail, P.S.; Teluguntla, P.; Xiong, J.; Gumma, M.K.; Congalton, R.G.; Yadav, K. Mapping cropland extent of Southeast and Northeast Asia using multi-year time-series Landsat 30-m data using a random forest classifier on the Google Earth Engine Cloud. Int. J. Appl. Earth Obs. Geoinf. 2019, 81, 110-124. [CrossRef]

22. Zurqani, H.A.; Post, C.J.; Mikhailova, E.A.; Schlautman, M.A.; Sharp, J.L. Geospatial analysis of land use change in the Savannah River Basin using Google Earth Engine. Int. J. Appl. Earth Obs. Geoinf. 2018, 69, 175-185. [CrossRef]

23. Liu, X.; Hu, G.; Chen, Y.; Li, X.; Xu, X.; Li, S.; Pei, F.; Wang, S. High-resolution multi-temporal mapping of global urban land using Landsat images based on the Google Earth Engine Platform. Remote Sens. Environ. 2018, 209, 227-239. [CrossRef] 
24. Dong, J.; Xiao, X.; Menarguez, M.A.; Zhang, G.; Qin, Y.; Thau, D.; Biradar, C.; Moore, B. Mapping paddy rice planting area in northeastern Asia with Landsat 8 images, phenology-based algorithm and Google Earth Engine. Remote Sens. Environ. 2016, 185, 142-154. [CrossRef]

25. Tang, Z.; Li, Y.; Gu, Y.; Jiang, W.; Xue, Y.; Hu, Q.; LaGrange, T.; Bishop, A.; Drahota, J.; Li, R. Assessing Nebraska playa wetland inundation status during 1985-2015 using Landsat data and Google Earth Engine. Environ. Monit. Assess. 2016, 188, 654. [CrossRef]

26. Hird, J.; DeLancey, E.; McDermid, G.; Kariyeva, J.; Hird, J.N.; DeLancey, E.R.; McDermid, G.J.; Kariyeva, J. Google Earth Engine, Open-Access Satellite Data, and Machine Learning in Support of Large-Area Probabilistic Wetland Mapping. Remote Sens. 2017, 9, 1315. [CrossRef]

27. Zhang, H.; Gorelick, S.M.; Zimba, P.V.; Zhang, X. A remote sensing method for estimating regional reservoir area and evaporative loss. J. Hydrol. 2017, 555, 213-227. [CrossRef]

28. Zou, Z.; Xiao, X.; Dong, J.; Qin, Y.; Doughty, R.B.; Menarguez, M.A.; Zhang, G.; Wang, J. Divergent trends of open-surface water body area in the contiguous United States from 1984 to 2016. Proc. Natl. Acad. Sci. USA 2018, 115, 3810-3815. [CrossRef]

29. Tulbure, M.G.; Broich, M.; Stehman, S.V.; Kommareddy, A. Surface water extent dynamics from three decades of seasonally continuous Landsat time series at subcontinental scale in a semi-arid region. Remote Sens. Environ. 2016, 178, 142-157. [CrossRef]

30. Mcfeeters, S.K. The use of the Normalized Difference Water Index (NDWI) in the delineation of open water features. Int. J. Remote Sens. 1996, 17, 1425-1432. [CrossRef]

31. $\mathrm{Xu}, \mathrm{H}$. Modification of normalised difference water index (NDWI) to enhance open water features in remotely sensed imagery. Int. J. Remote Sens. 2006, 27, 3025-3033. [CrossRef]

32. Feyisa, G.L.; Meilby, H.; Fensholt, R.; Proud, S.R. Automated Water Extraction Index: A new technique for surface water mapping using Landsat imagery. Remote Sens. Environ. 2014, 140, 23-35. [CrossRef]

33. Gómez, C.; White, J.C.; Wulder, M.A. Optical remotely sensed time series data for land cover classification: A review. ISPRS J. Photogramm. Remote Sens. 2016, 116, 55-72. [CrossRef]

34. Khatami, R.; Mountrakis, G.; Stehman, S.V. A meta-analysis of remote sensing research on supervised pixel-based land-cover image classification processes: General guidelines for practitioners and future research. Remote Sens. Environ. 2016, 177, 89-100. [CrossRef]

35. Tucker, C.J. Red and photographic infrared linear combinations for monitoring vegetation. Remote Sens. Environ. 1979, 8, 127-150. [CrossRef]

36. Huete, A.; Didan, K.; Miura, T.; Rodriguez, E.P.; Gao, X.; Ferreira, L.G. Overview of the radiometric and biophysical performance of the MODIS vegetation indices. Remote Sens. Environ. 2002, 83, 195-213. [CrossRef]

37. Zhou, Y.; Dong, J.; Xiao, X.; Liu, R.; Zou, Z.; Zhao, G.; Ge, Q. Continuous monitoring of lake dynamics on the Mongolian Plateau using all available Landsat imagery and Google Earth Engine. Sci. Total Environ. 2019, 689, 366-380. [CrossRef]

38. Han, X.; Chen, X.; Feng, L. Four decades of winter wetland changes in Poyang Lake based on Landsat observations between 1973 and 2013. Remote Sens. Environ. 2015, 156, 426-437. [CrossRef]

39. Wang, Y.; Ma, J.; Xiao, X.; Wang, X.; Dai, S.; Zhao, B. Long-Term Dynamic of Poyang Lake Surface Water: A Mapping Work Based on the Google Earth Engine Cloud Platform. Remote Sens. 2019, 11, 313. [CrossRef]

40. Wu, G.; Liu, Y. Mapping Dynamics of Inundation Patterns of Two Largest River-Connected Lakes in China: A Comparative Study. Remote Sens. 2016, 8, 560. [CrossRef]

41. Rao, P.; Jiang, W.; Hou, Y.; Chen, Z.; Jia, K. Dynamic Change Analysis of Surface Water in the Yangtze River Basin Based on MODIS Products. Remote Sens. 2018, 10, 1025. [CrossRef]

42. Cui, L.; Wang, L.; Lai, Z.; Tian, Q.; Liu, W.; Li, J. Innovative trend analysis of annual and seasonal air temperature and rainfall in the Yangtze River Basin, China during 1960-2015. J. Atmos. Sol. Terr. Phys. 2017, 164, 48-59. [CrossRef]

43. Sun, Z.; Zhu, X.; Pan, Y.; Zhang, J.; Sun, Z.; Zhu, X.; Pan, Y.; Zhang, J. Assessing Terrestrial Water Storage and Flood Potential Using GRACE Data in the Yangtze River Basin, China. Remote Sens. 2017, 9, 1011. [CrossRef]

44. Vermote, E.; Justice, C.; Claverie, M.; Franch, B. Preliminary analysis of the performance of the Landsat 8/OLI land surface reflectance product. Remote Sens. Environ. 2016, 185, 46-56. [CrossRef] 
45. Ashouri, H.; Hsu, K.-L.; Sorooshian, S.; Braithwaite, D.K.; Knapp, K.R.; Cecil, L.D.; Nelson, B.R.; Prat, O.P. PERSIANN-CDR: Daily Precipitation Climate Data Record from Multisatellite Observations for Hydrological and Climate Studies. Bull. Am. Meteorol. Soc. 2015, 96, 69-83. [CrossRef]

46. Gong, P.; Wang, J.; Yu, L.; Zhao, Y.; Zhao, Y.; Liang, L.; Niu, Z.; Huang, X.; Fu, H.; Liu, S.; et al. Finer resolution observation and monitoring of global land cover: First mapping results with Landsat TM and ETM+ data. Int. J. Remote Sens. 2013, 34, 2607-2654. [CrossRef]

47. Zhu, Z.; Wang, S.; Woodcock, C.E. Improvement and expansion of the Fmask algorithm: Cloud, cloud shadow, and snow detection for Landsats 4-7, 8, and Sentinel 2 images. Remote Sens. Environ. 2015, 159, 269-277. [CrossRef]

48. Zhu, Z.; Woodcock, C.E.; Holden, C.; Yang, Z. Generating synthetic Landsat images based on all available Landsat data: Predicting Landsat surface reflectance at any given time. Remote Sens. Environ. 2015, 162, 67-83. [CrossRef]

49. Donchyts, G.; Schellekens, J.; Winsemius, H.; Eisemann, E.; van de Giesen, N. A 30 m Resolution Surface Water Mask Including Estimation of Positional and Thematic Differences Using Landsat 8, SRTM and OpenStreetMap: A Case Study in the Murray-Darling Basin, Australia. Remote Sens. 2016, 8, 386. [CrossRef]

50. Qiao, B.; Zhu, L.; Yang, R. Temporal-spatial differences in lake water storage changes and their links to climate change throughout the Tibetan Plateau. Remote Sens. Environ. 2019, 222, 232-243. [CrossRef]

51. Song, C.; Huang, B.; Ke, L.; Richards, K.S. Remote sensing of alpine lake water environment changes on the Tibetan Plateau and surroundings: A review. ISPRS J. Photogramm. Remote Sens. 2014, 92, 26-37. [CrossRef]

52. Zhang, G.; Yao, T.; Xie, H.; Zhang, K.; Zhu, F. Lakes' state and abundance across the Tibetan Plateau. Chin. Sci. Bull. 2014, 59, 3010-3021. [CrossRef]

53. Wang, X.; Wang, W.; Jiang, W.; Jia, K.; Rao, P.; Lv, J. Analysis of the Dynamic Changes of the Baiyangdian Lake Surface Based on a Complex Water Extraction Method. Water 2018, 10, 1616. [CrossRef]

54. Zhou, Y.; Ma, J.; Zhang, Y.; Li, J.; Feng, L.; Zhang, Y.; Shi, K.; Brookes, J.D.; Jeppesen, E. Influence of the three Gorges Reservoir on the shrinkage of China's two largest freshwater lakes. Glob. Planet. Chang. 2019, 177, 45-55. [CrossRef]

55. Deng, Y.; Jiang, W.; Tang, Z.; Li, J.; Lv, J.; Chen, Z.; Jia, K. Spatio-Temporal Change of Lake Water Extent in Wuhan Urban Agglomeration Based on Landsat Images from 1987 to 2015. Remote Sens. 2017, 9, 270. [CrossRef] 